Tjalling C. Koopmans Research Institute

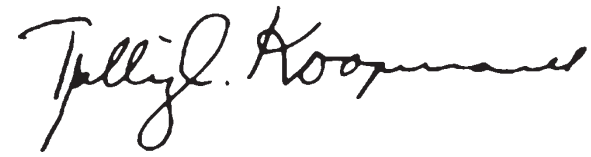

Discussion Paper Series nr: 01-03

\title{
Explaining the Wealth Holdings of Different Cohorts: Productivity Growth and Social Security
}

Arie Kapteyn

Rob Alessie

Annamaria Lusardi 


\title{
Tjalling C.Koopmans Research Institute Utrecht School of Economics Utrecht University
}

Vredenburg 138

3511 BG Utrecht

The Netherlands

telephone (0031) 0302539800

fax (0031) 0302537373

website www.koopmansinstitute.uu.nl

The Tjalling C. Koopmans Institute is the research institute and research school of the Utrecht School of Economics.

It was founded in 2003, and named after Professor Tjalling C. Koopmans, the Dutch born Nobel Prize laureate in economics in 1975.

In the discussion papers series the Koopmans Institute publishes results of ongoing research for early dissemination of research results, and to enhance discussion with colleagues.

Please sent any remarks or questions on the Koopmans institute, or this series to P.vanDriel@econ.uu.nl

\author{
How to reach the authors \\ Arie Kapteyn \\ RAND \\ P.O. Box 2138 \\ Santa Monica \\ CA 90407-2138 USA \\ E-mail: kapteyn@rand.org \\ Rob Alessie \\ Utrecht School of Economics \\ Utrecht University \\ Vredenburg 1383511 BG Utrecht \\ The Netherlands \\ E-mail: r.alessie@econ.uu.nl \\ Annamaria Lusardi \\ Department of Economics \\ Dartmouth College \\ Hanover \\ NH 03755, USA. \\ Tel: 603-646-2099 \\ Fax: 603-646-2122. \\ E-mail: Annamaria.Lusardi@Dartmouth.edu
}

This paper can be downloaded at: www.koopmansinstitute.uu.nl 


\title{
Explaining the Wealth Holdings of Different Cohorts: Productivity Growth and Social Security
}

\author{
Arie Kapteyn ${ }^{a}$ \\ Rob Alessie Dartmouth College ${ }^{\mathrm{b}}$ \\ Annamaria Lusardic \\ ${ }^{a}$ RAND \\ bUtrecht University \\ 'Dartmouth College
}

(This revision: July 2003)

\begin{abstract}
It is well-known that individuals born in different periods of time (cohorts or generations) exhibit different wealth accumulation paths. While previous studies have used cohort dummies to proxy for this fact, research in this area suffers from a serious identification problem, i.e., how to disentangle age, time, and cohort effects from a simple cross-section or a time series of cross-sections. Furthermore, the use of cohort dummies leaves unexplained the reasons for the differences across cohorts.

In this paper, we go beyond the simple use of cohort dummies to capture the differences in wealth holdings across generations. We use basic economic theory to propose two indicators of the economic conditions under which households accumulate wealth. The first one represents productivity differences across cohorts: the aggregate level of gross national product per capita around the time the head of the household entered the labor market. The second measure summarizes the changes in Social Security during the head of household's working life. Using panel data from the Dutch Socio-Economic Panel, we show that productivity growth can explain all the cohort effects present in income data, while productivity growth and the generosity of Social Security can explain all the cohort effects present in household net worth. Thus, cohort effects can be traced back to past economic conditions and we do not need to resort to differences in preferences or other reasons to explain the differences in wealth holdings across generations.
\end{abstract}

Keywords: Wealth Accumulation, Life-Cycle Models, Social Security

JEL classification: D91, C23

\section{Acknowledgement}

We would like to thank our editor, Steve Pischke, two anonymous referees, and Orazio Attanasio, Martin Browning, David Card, Jim Davies, Jeff Grogger, Jim Heckman, Mike Hurd, Tullio Jappelli, Anders Klevmarken,Thierry Magnac, André Masson, Robert Moffit, Karl Scholz, Jon Skinner, Steve Venti, and seminar participants at many universities and conferences for very helpful suggestions and comments. We alone are responsible for errors. 


\section{Introduction}

Many reasons have been proposed in the literature to explain why individuals born in different time periods have different paths of saving and wealth accumulation. People can differ in their tastes. For example, generations who lived through the Great Depression or World War II may be thriftier and more alert to risk than other generations. Additionally, generations could be different due to the diversity of economic conditions during their working lives. In this paper, we argue that the latter reason explains why wealth differs across cohorts. To do so, we need to be able to distinguish among age, time, and cohort effects.

Empirically, one cannot disentangle age and cohort effects in wealth in cross-sectional data. Shorrocks (1975) was the first to point out that productivity growth creates differences in household wealth holdings across generations. Thus, solely on the basis of cross-sectional data, one cannot study issues such as whether the elderly decumulate wealth after retirement. A few authors have used time series of cross sections to study the behavior of wealth or saving. ${ }^{1}$ They estimate a wealth or saving equation as a function of age dummies (or a polynomial in age) and cohort dummies. Additionally, one would like to include time dummies, e.g. to allow for macro shocks. However, this introduces an identification problem: calendar time is simply equal to year of birth (cohort) plus age.

Some authors, such as Attanasio (1998), simply acknowledge this identification problem and show that one can only identify the age profile of the changes in saving but not the age profile of saving itself. Others impose restrictions on the time dummies. The leading approach is the one of Deaton and Paxson (1994a,b) in the context of the life-cycle permanent income hypothesis (LC-PIH) for consumption. They assume that the coefficients corresponding to the time dummies add up to zero and are orthogonal to a time trend. One possible justification for this assumption is that time effects are only due to macro shocks and average out over time. This assumption might be reasonable if the LC-PIH provides a good characterization of household behavior and one has panel data or a time series of cross-sections available with many waves. In our dataset, as is generally the case in existing empirical studies, the number of waves is modest $(T=11)$. Furthermore, our sample period is characterized by dramatic changes in house and stock prices. Since net worth obviously depends on these prices, we have to rely on other identifying assumptions than the one suggested by Deaton and Paxson.

We address the identification problem by exploiting the predictions of a fairly standard version of the LC-

\footnotetext{
${ }^{1}$ See Attanasio (1998), Deaton and Paxson (1994a), Venti and Wise (1997), and Jappelli (1999).
} 
PIH to explicitly model the cohort effect. ${ }^{2}$ We show that productivity growth and changes in Social Security (SS) together can explain the differences in wealth across cohorts. Productivity differences generate differences in permanent income across cohorts, which then feed into the wealth accumulation of households belonging to different generations. Changes in SS provisions alter the time path of income over one's life cycle and hence affect the need to save for retirement. In our empirical work, productivity of a cohort is proxied by the level of real gross national product per capita (RGNPC) when the head of the household entered the labor market (which we take to be between age 16 through 25). The effect of SS is proxied by a measure summarizing the changes in the SS system during the head of household's life. The inclusion of productivity growth in the regression for household non-capital income renders cohort dummies statistically insignificant. Thus, our productivity measures appear to capture all cohort effects in income. In turn, permanent income, which include these productivity effects, and our constructed SS variable can explain all cohort differences in net worth.

The advantages of using these measures rather than cohort dummies are several. Not only do we get around the identification problem, but we can also determine more clearly the causes for the differences in income and wealth holdings across cohorts. While many potential reasons have been proposed for explaining these differences, simple cohort dummies cannot distinguish, for example, between differences in economic circumstances and differences in preferences. Furthermore, the simple theoretical framework described in the paper highlights that it is very restrictive to use cohort dummies to model cohort effects, since it is easy to envisage cases where the effect is not simply additive, but, as we illustrate for the case of SS, there are interactions between cohort and age effects. In addition, cohort dummies can be rather difficult to interpret when some past economic conditions (productivity growth) lead to an increase in wealth across cohorts, while others (increases in the generosity of SS) lead to a decrease. For policy purposes, it may be very important to disentangle those effects in the data. Our simple economic framework allows for that.

We estimate our model using panel data from the Netherlands. This is a country whose historical conditions are ideal to study the effects of productivity growth and SS. The Netherlands experienced a steady growth after World War II. At the same time, it also built up a very extensive welfare system. ${ }^{3}$ We find that past economic circumstances can explain the variation in paths of wealth accumulation across cohorts. Thus, we do not need to rely on differences in preferences, e.g. differences in thriftiness, to explain differences in

\footnotetext{
2 There are several earlier papers that model cohort effects as a function of underlying explanatory variables. Important precursors to our approach are Jonsson and Klevmarken (1978), Weiss and Lillard (1978), Heckman and Robb (1985), and MaCurdy and Mroz (1995).

${ }^{3}$ For details, see van Ark, de Haan, and de Jong (1996).
} 
wealth across cohorts. In particular, our empirical work reinforces the findings of others, such as Shorrocks (1975) and Feldstein $(1974,1996)$, that productivity growth and Social Security are important determinants of wealth.

The paper is organized as follows: In Section 2, we present a simple theoretical framework in which we illustrate the effects of productivity growth and SS on wealth. In Section 3, we introduce the data set and describe the main features of wealth and income over the life cycle. In Section 4, we describe the econometric specification for after-tax household non-capital income and present our empirical results. In Section 5, we report the econometric specification and empirical results for wealth and in Section 6 we provide some brief conclusions.

\section{Theoretical framework}

The theoretical framework underlying our analysis is the simple LC-PIH. In this model, agents accumulate wealth to smooth consumption over the life cycle. Under some restrictive assumptions (e.g. quadratic preferences, complete certainty, equality of the rate of time preference and the interest rate), ${ }^{4}$ we can derive closed-form solutions for both consumption and wealth. The expression for consumption is as follows:

$$
c_{t}=Y_{p}=\left(\sum_{\tau=t}^{L}(1+r)^{t-\tau}\right)^{-1}\left((1+r) A_{t-1}+\sum_{\tau=t}^{L}(1+r)^{t-\tau} y_{\tau}\right)
$$

where $c_{t}$ and $y_{t}$ indicate consumption and non-capital income at age $t, r$ is the interest rate which is assumed to be fixed, $A$ is non-human bequeathable wealth (non-pension and non-SS wealth) and $L$ is the length of life. Equation 1 states that consumption is equal to permanent income, i.e., the present discounted value of lifetime resources. Wealth at age $\mathrm{t}$ is equal to accumulated saving:

$$
A_{t}=(1+r)^{t-1}\left((1+r) A_{0}+\sum_{\tau=1}^{t}(1+r)^{1-\tau}\left(y_{\tau}-Y_{p}\right)\right)
$$

If we introduce uncertainty, an expression like (2) becomes considerably more complicated since wealth at age $t$ becomes a function of deviations between expected incomes in the past and their realizations, and of changes in expectations (see equation (A.5) in Appendix A).

It can be seen that if, due to a permanent positive shock, expectations of future income get revised

\footnotetext{
${ }^{4}$ Most results concerning the effect of productivity growth can be obtained while relaxing some of these assumptions, see Appendix A.
} 
upwards, current consumption increases and this results in lower saving. A prime example of changing expectations about future incomes is provided by the introduction and extensions of the SS system.

\subsection{Social Security}

In western societies, the introduction of an extensive SS system has greatly reduced the need to save for old age. In the Netherlands, a universal SS system was instituted in 1957 and our data set includes households who were in the labor market well before the introduction of the system. ${ }^{5}$ The SS system is essentially payas-you-go. SS wealth represents a very important component of total household wealth holdings. According to our calculations, total net worth (i.e., bequeathable and non-bequeathable wealth) for households whose head is 65-69 years old (in 1987) is approximately Dutch Guilders (Dfl) 440,000, of which more than Dfl. 228,000 is accounted for by SS (medians are Dfl. 354,200 and Dfl. 246,700). For other age groups we find similar results. Thus, about half of total wealth holdings of the elderly is accounted for by SS. ${ }^{6}$

Appendix A investigates in detail the effect of the introduction and changes in SS on consumption and wealth accumulation in the framework of the LC-PIH. Here we only sketch the main argument. The key assumption is that the introduction of SS leads to a permanent (and unanticipated) increase in income at retirement. We consider two cases; in the first one, pre-retirement income is unchanged and in the second, pre-retirement income falls because a payroll tax is levied to finance SS.

We start by considering the case where pre-retirement income is unchanged. Given the unanticipated increase in life-time resources, consumption increases while saving decreases. Thus, the unanticipated change in SS creates a reduction in household (private) wealth. In Figures $1 \mathrm{a}$ and $1 \mathrm{~b}$, we provide a simple illustration of the effects generated by the introduction of SS. For simplicity we assume that, after its introduction, the level of SS benefits remains constant at a flat amount (about Dfl 15,000). We consider three individuals, all with identical lifetime non-capital incomes before retirement (which starts after age 65). The first individual, who is a representative of the "old cohort," lived in a time without SS and his/her income after retirement drops to zero. His/her consumption is constant across the whole life-cycle and equal to about Dfl. $26,000$. The second individual, a representative of the "middle aged cohort," was 50 years old when the SS system

\footnotetext{
5 The General Old Pension Act (AOW) of 1957 introduced Social Security to the entire Dutch population. Some pension provisions were present from 1947 onwards, but they were restricted to some small groups of the population, mainly the very poor and civil servants. See, also, van Ark, de Haan, and de Jong (1996).

${ }^{6}$ For details, see Alessie, Lusardi, and Kapteyn (1995).
} 
was first introduced. He/she will receive SS benefits at retirement. The introduction of SS at age 50 represents an unanticipated increase in life-time resources. Consumption and permanent income of this individual increase. The size of the increase can easily be derived from equation (1). The third individual, a representative of the "young cohort," was 35 when SS was introduced. For this individual as well, the introduction of SS represented an unanticipated increase in life-time resources and his/her consumption shifts upward as well, but not by as much as for the middle aged individual, since the increase in life-time resources has to be spread out over a longer remaining life-time.

The shift in consumption affects saving rates. Since pre-retirement non-capital income is not affected by the introduction of SS, pre-retirement saving goes down by the same amount consumption goes up. Thus, pre-retirement wealth decreases by an amount which is equal to the discounted sum of past and current changes in permanent income (or consumption). The implied wealth profiles are given in Figure $1 \mathrm{~b}$. In comparison with the old cohort, the effect of SS on wealth for the middle aged cohort at different ages is given by the vertical difference between the curve ACD and the curve AFGD. Similarly, the vertical difference between ACD and ABED represents the effect of the introduction of SS on the wealth accumulation of the youngest cohort. In Appendix A, we show that this effect, which is summarized by the variable $D S S_{t}$, can be written as a function of the SS benefit levels, the interest rates, the retirement age, and the age of death (see (A.8) and (A.11) in Appendix A). While the graphs are based on the assumption that SS benefits remain constant over time, in Appendix A and in our empirical work, we allow SS benefits to change over time.

The graphical analysis highlights another important aspect of the introduction of SS. The displacement effect created by SS depends not only on the year when SS was introduced but also on the age of the individual at that time. In other words, there is an interaction between age and cohort effects, which cannot simply be summarized by cohort dummies.

We next consider the case where pre-retirement income falls because SS is financed through a payroll tax. The effects on wealth accumulation are qualitatively the same. This follows directly from the certainty equivalent set-up. Given the age of retirement, savings during the working life are simply a function of the difference in incomes between retirement and the working life. An increase in income during retirement therefore has the same effect as a reduction in income during the working life.

An econometric analysis of equation (2) would require the complete income history of each individual and the history of the variables that are relevant for wealth (such as taste shifters, demographics, etc.). We do not have such data at our disposal. Rather, we have a panel of households covering eleven years of wealth 
information (see Section 3 for a description of the data). To be able to estimate an equation like (2), we therefore need to apply some approximations. As a first approximation, we assume that wealth at the beginning of life, $A_{0}$, can be ignored. Furthermore, upon dividing both sides of equation (2) by permanent income we obtain:

$$
\frac{A_{t}}{Y_{p}}=(1+r)^{t-1}\left(\sum_{\tau=1}^{t}(1+r)^{1-\tau} \frac{\left(y_{\tau}-Y_{p}\right)}{Y_{p}}\right)
$$

The right hand side can be approximated by a function of age and other variables that may affect the relative difference of current income and permanent income. Since we use household data, these other variables may include family composition, education of the head of household, etc.

The introduction of a displacement effect due to the introduction or changes in SS into (3) is straightforward. Let $D S S_{t}$ be the additive displacement effect of SS on wealth at age $t$. We sketched above how this variable is constructed. Then (3) is replaced by

$$
\frac{A_{t}}{Y_{p}}=(1+r)^{t-1}\left(\sum_{\tau=1}^{t}(1+r)^{1-\tau} \frac{\left(y_{\tau}-Y_{p}\right)}{Y_{p}}\right)-\alpha \frac{D S S_{t}}{Y_{p}}
$$

If the LC-PIH is correct and if the introduction of and changes in SS do not affect pre-retirement income, then $\alpha=1$. If pre-retirement income goes down, the parameter $\alpha$ takes a value between 0 and 1 . In appendix A, we show that, when SS is financed as a pay-as-you-system, the parameter $\alpha$ is approximately equal to the old age dependency ratio (i.e., the ratio of the number of SS recipients to those who pay SS taxes). In the Netherlands, this ratio is equal to about 0.2 .

While the basic framework here is the LC-PIH, qualitatively the findings concerning the effects of SS on consumption and savings will also hold under different models, such as a precautionary saving model (assuming CARA preferences) or a model with uncertain life-time or a bequest motive. The effect of these extensions is to induce extra motives to save during the working life and to reduce decumulation after retirement (see, e.g., Hurd (1989, 1998), and Browning and Lusardi (1996)). However, SS has effects on wealth accumulation in the same direction as in the current model. One should also note that the strength of other saving motives will depend on the institutional environment. For instance, Samwick (2003) finds that during the first phase of the life cycle, buffer stock saving is much more important than retirement saving. However, this conclusion is based on U.S. data. With its very extensive welfare system and employment protection, income uncertainty in the Netherlands is substantially lower than the US and buffer stock saving 
may be expected to be quantitatively less important.

Another simplification in the model introduced above is the absence of labor supply responses, as utility is assumed to depend on consumption only. In a model with both consumption and leisure in the utility function in a non-separable way, one expects an effect of the introduction of SS on the timing of retirement and hence on the savings rate during one's working life, since the introduction of SS increases lifetime resources for the older cohorts (the expected present discounted value of their SS benefits is greater than the value of the extra payroll tax). This increase in lifetime resources may conceivably be consumed in the form of more leisure, e.g., through early retirement. This in itself increases the need to save for retirement and hence may offset the depressing effect of SS on savings. ${ }^{7}$ It is not likely that this factor plays an important role in the Netherlands. Although early retirement has boomed since the eighties, replacement rates typically offered to those taking early retirement have been very high (on the order of 80 or $90 \%$ after tax), which substantially reduces the need to save for retirement purposes.

To make equation (4) fully operational we have to add taste shifters and other variables affecting wealth accumulation. But more importantly, we have to model the income process for different cohorts.

\subsection{Productivity growth}

To examine the effect of productivity growth on the wealth holdings of different cohorts, we compare wealth levels at age $\mathrm{t}$ of two different generations: $c_{l}$ (the younger cohort) and $\mathrm{c}_{2}$ (the older cohort) in the presence of productivity growth. We consider a simple case of productivity growth by modeling the income of households $h$ and $i$ belonging to two different cohorts as follows:

$$
\ln y_{t h}^{c 1}-\ln y_{t i}^{c 2}=G_{c l}^{c 2}+\omega_{t h i}
$$

where $G_{c l}^{c 2}$ is a constant specific to the cohorts $c_{1}$ and $c_{2}$ and $\omega_{t h i}$ represents all other sources of differences between the incomes of households $h$ and $i$, e.g. differences in education of the household head, the number of earners, etc. Importantly, $\omega_{t h i}$ is not a function of the cohorts to which these households belong. Thus (5) states that, ceteris paribus, at any age $t$, the earnings of the two cohorts differ by a constant of proportionality, reflecting, for example, the higher salary at the start of the career of the younger cohort $c_{l}$. This assumption is clearly restrictive. For example, it assumes that different cohorts expect the same profile of income over the lifetime. However, other authors have used similar assumptions and it is important to test it against the

\footnotetext{
${ }^{7}$ See, for example, Feldstein (1974) and Diamond and Hausman (1984).
} 
data. $^{8}$

In our empirical work, we will relate the multiplicative cohort effect $G_{c l}^{c 2}$ to the value of RGNPC around the time the head of the household entered the labor market. Since we don't know when exactly the respondents in the panel entered the labor market, we allow the cohort effect to be a weighted average of RGNPC in the years covering the household head's ages 16 through 25.

\section{The data}

\subsection{Description of the Socio-Economic Panel}

The empirical analysis is based on the Netherlands Socio-Economic Panel (SEP), conducted by Statistics Netherlands. The SEP is a longitudinal household survey representative of the total population, excluding those living in special institutions like nursing homes. The first survey was conducted in April 1984. The same households were interviewed again in October 1984 and then twice a year (in April and October) until 1989. In the years since 1990, all information has been collected in one interview, in May of each year. In the October interview, information was collected on socio-economic characteristics: demographics, income, labor market participation and hours of work. In the April interview, information was collected on socio-economic characteristics as in the October interview, but, rather than collecting data about income, from 1987 onwards, information was collected on assets and liabilities. In this paper, we use income data from 1984 until 1997 , and wealth data from 1987 until 1998. While income is measured retrospectively, i.e., income questions in a given year pertain to incomes in the previous calendar year, wealth data pertain to April of the current year. All monetary units have been deflated using the Consumer Price Index and are expressed in 1987 guilders.

An evaluation of the quality of the SEP data and a comparison with macro statistics or other micro data sets is reported in Alessie, Lusardi and Aldershof (1997). We can briefly summarize their findings as follows: the data on some major components of wealth, such as housing, mortgage debt, and checking accounts are well reported in the SEP and compare reasonably well with aggregate statistics. However, some other components, in particular stocks, bonds, and savings accounts seem under-reported in the SEP, and the level of measurement error may also change over time. This problem is typical of wealth surveys and can be found in other similar data sets.

We have deleted from the sample those cases with missing or incomplete responses in the assets and

\footnotetext{
${ }^{8}$ See Deaton (1999) for a similar assumption about the impact of productivity growth on the income process. See, however, the discussion about productivity growth and saving in Viard (1993).
} 
liabilities components and in the demographics. ${ }^{9}$ We have also excluded the self-employed from the sample. The quality of wealth data is very poor for these households, and additionally, wealth data for the selfemployed are not available after 1989. Due to these selections, we find that both low and high wealth households have a tendency to drop out of the sample. We will take selectivity into account in our empirical work.

We start the empirical analysis by reporting some basic facts about income. In particular, we first examine whether there is evidence of productivity growth in the raw data. This analysis provides useful insights to perform the empirical work. We have re-arranged the data as follows: We have defined twelve cohorts by choosing a 5 year-of-birth interval and have considered all households, from the ones born in 1911-15 ${ }^{10}$ (they are 72-76 years old in 1987) until the ones who represent the youngest generation (they are born in 1966-70). ${ }^{11}$

In Figure 2, we plot mean household non-capital income from 1984 to 1997 for each cohort. For clarity, the graphs only indicate the average year when the head of the household was born (for example, "38" refers to heads of households born between 1936 and 1940). The vertical difference between lines measures the "cohort-time" effect. The difference along the same line measures the "age-time" effect. We use this terminology to emphasize that it is not possible to disentangle age from cohort and time effects in these figures.

We find that non-capital income has been increasing strongly across cohorts. A big cohort-time effect is between the cohort born between 1936-1940 and the one born between 1931-1935. ${ }^{12}$ The age-time effect is also large. In particular, the young and middle-age households experience a sizable increase in non-capital income as they move along in their career.

The effects across cohorts could simply reflect changes in the labor force participation of Dutch households. For example, female labor force participation has been increasing over time, and the fraction of families with two earners has increased considerably. The SEP data show that there has been a substantial

\footnotetext{
${ }^{9}$ In many cases, missing data on assets and liabilities could be imputed. See Camphuis (1993) for more details on the data imputation and Alessie, Lusardi and Aldershof (1997) for a description of the criteria used to calculate total net worth.

${ }^{10}$ Whenever we speak of the age of a household we mean the age of the head of the household.

${ }^{11}$ For a detailed explanation of this methodology, see Browning, Deaton and Irish (1985) and Attanasio (1998). Note that we have deleted the households whose head is younger than 22 (in 1987) to exclude the persons still in school, and the households whose head is older than 76 (in 1987) to partly avoid the strong correlation between mortality and wealth holdings. See also Attanasio and Hoynes (2000).

${ }^{12}$ Historically, wage controls were implemented in the 1950s, but these controls were lifted in the early 1960s and wages grew substantially in that period. Growth came to a halt in the 1970s with two severe recessions.
} 
increase in the labor force participation among young couples and there is a strong cohort-time effect for couples whose head is 50 years or younger. However, these effects are still present in the per earner income data. Thus, there is evidence of productivity growth in individual income.

Turning to wealth, we use two measures of household wealth: financial net worth and total net worth. The first measure is obtained by summing the amounts reported in checking accounts, saving certificates, bonds, stocks, options and other such securities, cars, claims against private persons and subtracting the total amount of debt (which is composed of loans and credit, installment credit, other debt and loans) ${ }^{13}$ Total net worth is obtained by adding to financial net worth the value of the house and other real estate, the home-owner's insurance policy, and subtracting the mortgage debt. We consider these two measures of wealth to assess the importance and role of housing equity.

In Figure 3a, we plot mean net worth from 1987 to 1998 for each cohort. As for income, there are substantial cohort-time effects as well as age-time effects in total net worth. Within the same cohort, mean net worth is steadily increasing over time. This is particularly true for the younger and middle-aged cohorts, but even for some elderly, mean net worth continues to increase over time. As expected, a large part of the wealth accumulation is done by the middle age cohorts (households born between 1931 and 1945). For example, the increase in mean net worth over the 11-year period is as big as Dfl. 134,000 for the generation born between 1946 and 1950. Figure 3b, which displays mean financial wealth across cohorts, confirms the findings of Figure 3a. However, for the older cohorts, the relative increase in average financial wealth is more pronounced than that of net worth. However, this may simply result from differential mortality among the very old (Hurd (1990)). Looking across cohorts, we find that there are also large differences in wealth accumulation. The biggest cohort-time effects in net worth are experienced by the households born between 1931 and 1940. These effects are present both in the mean and in the median. Cohort-time effects are also present in financial net worth. Time effects alone could also be relevant in affecting the size and magnitude of the differences in wealth accumulation across cohorts.

Given the differences between financial net worth and total net worth, we have investigated housing equity separately. Housing is an important asset in household portfolios. However, strong cohort-time effects remain in non-housing wealth (see Figure 3b). We have also looked at the effects of capital gains in bonds and stocks on wealth accumulation. Excluding capital gains on housing and stocks, we found that the cohort-time effects in wealth remain sizable. It is therefore unlikely that cohort-time effects can be explained simply by a change in housing prices or by other time effects, while productivity growth and other economic circumstances

\footnotetext{
${ }^{13}$ The reason why we include durables, such as cars, in this definition of wealth is because we cannot distinguish between car loans and other debts.
} 
remain potentially important explanations for the pattern of wealth holdings across cohorts.

\section{Econometric specification for income}

In the econometric analysis, we take an unbalanced panel and consider household income between 1984 and 1997 and household wealth between 1987 and 1998. As equation (3) makes clear, to explain wealth accumulation of households, we need to first model non-capital incomes over the life cycle. In doing so, we will seek to account for cohort differences in productivity. We consider the following fairly simple model to describe household income:

$$
\ln \left(y_{s h}\right)=\zeta_{0}+\sum_{i=1}^{\operatorname{Imax}} \zeta_{i} s_{i}\left(a g e_{s h}^{i}\right)+\sum_{\tau=1985}^{1997} \gamma_{\tau} T D_{\tau s}+\sum_{i=2}^{14} \Delta_{i} L D_{i s h}+\sum_{i=2}^{13} \phi_{i} S D_{i s h}+X_{s h}^{\prime} \beta+u_{h}+\epsilon_{s h}
$$

where

$$
\begin{aligned}
& s=\text { time index, } \mathrm{s}=1984, . ., 1997 \\
& h=\text { household index; } \\
& y_{s h}=\text { non-capital income of household } \mathrm{h} \text { in year } s ; \\
& a g e_{s h}=\text { age of the head of the household in year } s ; \\
& s_{i}=\text { linear spline function; } \\
& T D_{\tau s}=\text { time dummies, equal to one if } \tau=s, \text { and zero otherwise; } \\
& L D_{i s h}=\text { learning dummies; } \\
& S D_{i s h}=\text { selectivity dummies; } \\
& X_{s h}=\text { vector of demographic and socio-economic characteristics; } \\
& u_{h}=\text { individual effect; } \\
& \epsilon_{s h}=\text { random i.i.d. error term with mean zero and variance } \sigma^{2}{ }_{\epsilon} .
\end{aligned}
$$

In equation (6), we specify a flexible relationship between income and age by considering a linear spline with a number of knots to be determined by the data. We have included in the vector of demographic and socio-economic characteristics, $X_{s h}$, the following variables: number of adults in the households, number of children in different age groups ( 6 or younger, between 7 and 12, between 13 and 17, 18 years or older), the gender of the head of the household, and dummy variables indicating the education level of the head of the household (primary, lower secondary, higher secondary, and university education).

Selectivity dummies $\left(S D_{i s h}\right)$ are defined as follows: $S D_{i s h}=1$ if the household participates in year $s$ and participates at least one more time in the survey after period $s$. Otherwise the dummy is equal to zero. The dummies pick up the possibility that respondents who participate at least one more year are different from 
those who drop out.

To allow for the possibility of learning effects, "learning" dummies $\left(L D_{i s h}\right)$ have been included. Our motivation is that, as households participate in the survey, they become either better or worse (for example less careful) in answering the questionnaire. The learning dummies are defined by the number of times households participate in the survey. The first learning dummy for a household in a particular wave is equal to one if in this wave the household participates for the first time. The second learning dummy is equal to one if in this wave the household participates for the second time, etc. Since the sample period for the income equation covers 14 periods, the maximum number of times a household participates is equal to 14 . Notice that in a balanced panel, $L D_{i s h}$ is just a set of time dummies. In other words, one cannot distinguish between learning effects and, for example, macroeconomic shocks. However, we work with an unbalanced panel. A similar comment can be made regarding the selectivity dummies.

The individual-specific effect, $u_{h}$, in equation (6) represents unobserved heterogeneity. We want to allow for the possibility that the individual effects are correlated with other right-hand-side variables. It is wellknown after the work of Mundlak (1978) that this can be done in two equivalent ways. One possibility is to assume that individual effects are fixed and estimate them as individual parameters. The second possibility, which we choose, amounts to modeling the individual effect by making it dependent on household specific means of all time varying right-hand-side variables. Furthermore, we want to allow for cohort effects by making the individual effects dependent on the year of birth of the household head. Let $W_{s h}$ be the matrix of all time varying explanatory variables on the right hand side of (6), plus a column of ones. That is, $W_{s h}$ includes $X_{\mathrm{sh}}$, the time dummies, learning dummies, and selectivity dummies. Define $\bar{W}_{\mathrm{h}} \equiv 1 / \mathrm{S} \Sigma_{\mathrm{s}} W_{\text {sh, }}$ i.e., the time average of $W_{s h}$. We then model the individual effects as follows: ${ }^{14}$

$$
u_{h}=\bar{W}_{h}^{\prime} \gamma+\sum_{c=1912}^{1970} \delta_{c} C D_{c h}+\theta_{h}
$$

where $C D_{c h}=$ cohort dummies; $c$ = year of birth cohort index which goes from1912 to1970 (i.e. we include a full set of cohort dummies). Notice that in equation (7) we have not modeled explicitly the cohort effects (we return later to this issue). We assume that the individual effects $\theta_{h}$ are random and uncorrelated with the explanatory variables. The inclusion of individual effects has the additional advantage that it takes care of all selectivity that is dependent on time invariant factors. ${ }^{15}$

If we insert (7) into (6), we obtain an equation where income is a function of time, cohort, and age effects.

\footnotetext{
${ }^{14}$ Without loss of generality we can omit from $\bar{W}_{\mathrm{h}}$ the mean values of the age splines, since in a balanced panel the means are linearly related to cohort specific variables.

15 See Verbeek and Nijman (1992).
} 
The problem, however, is that, as mentioned before, we cannot disentangle age, cohort and time effects from each other. Deaton and Paxson (1994a,b) deal with this identification problem in a clever way. They assume that the coefficients corresponding to the time dummies add up to zero and are orthogonal to a time trend. Notice, however, that the model of Deaton and Paxson is observationally equivalent to a model in which one arbitrarily deletes one cohort, time or age dummy. In other words, Deaton and Paxson's model is justidentified.

In our approach, we explicitly model the cohort effects. We assume that the cohort effects are driven by productivity differences across generations, as represented by equation (5). We relate the multiplicative cohort effect to the value of RGNPC around the time the head of the household entered the labor market, which we take to be between ages 16 through 25 . Thus the productivity indicator for a household is a weighted average of RGNPC for the years that the household head was between 16 and 25. To impose some smoothness on the weights and, at the same time, maintain flexibility, we have modeled the weights as Almon lags. We let the degree of the Almon polynomial be determined by the data.

\subsection{Empirical results for income}

The estimation results of our preferred specification are summarized in Table 1. For clarity, we do not present the estimated coefficients for the demographic variables, time dummies, learning dummies, and selectivity dummies. Their statistical significance is summarized by $\chi^{2}$-tests presented at the bottom of the table. The preferred specification is the result of a sequence of specification tests. First of all, we estimate income regressions by education levels. A model with just additive education effects but no interactions is decisively rejected against the model presented in Table $1\left(\chi^{2}(306)=2,647, p=.000\right)$. A model with full age and education interactions but otherwise identical coefficients across education levels was also rejected $\left(\chi^{2}(261)=1,621, \mathrm{p}=.000\right)$. Across all education levels, the selectivity dummies appear to be jointly insignificant, while the learning dummies are only significant for education level 3 . The time dummies are significant for the highest education level.

The number of knots in the linear spline for age has been the result of specification testing against a model with a full set of age dummies. At 15 (equally spaced) knots, the specification cannot be rejected; the p-values for the four education levels are respectively $.312, .070, .350, .325$. We plot the implied age functions for the four education levels in Figure 4. Education level 4 clearly enjoys a steeper age income profile than the other three education levels. The age-income profiles of education levels 2 and 3 are rather similar. For education levels 1, 3 and 4, we observe a drop in income after age 55. This result can be explained by the rather generous disability and early retirement schemes which prevailed in the Netherlands during the eighties and nineties 
(see e.g. Kapteyn and De Vos (1998)). As mentioned before, these schemes provided high replacement rates.

Turning to the modeling of cohort effects, as we have explained in section 2 and the preceding subsection, our maintained hypothesis is that the cohort effects can be explained by productivity growth. The degree of the polynomial in the Almon lag has been determined by "testing down" until a further reduction in the degree of the polynomial was rejected against a more flexible specification. This procedure has led us to choose a quadratic. In other words, we consider a linear combination RGNPC at ages 16 through 25 of the form:

$$
\sum_{i=1}^{10} \beta_{i} Y_{26-i}
$$

where $y_{26-i}$ indicates RGNPC at age $26-i, i=1, \ldots 10$, and:

$$
\beta_{i}=\eta_{0}+\eta_{1} i+\eta_{2} i^{2}
$$

Inserting (9) into (8) yields:

$$
\begin{gathered}
\sum_{i=1}^{10} \beta_{i} Y_{26-i}=\eta_{0} \sum_{i=1}^{10} Y_{26-i}+\eta_{1} \sum_{i=1}^{10} i Y_{26-i}+\eta_{2} \sum_{i=1}^{10} i^{2} Y_{26-i} \\
\equiv \eta_{0} \text { rgnpc1 }+\eta_{1} \text { rgnpc } 2+\eta_{2} \text { rgnpc3 }
\end{gathered}
$$

with $r g n p c 1, \operatorname{rgnpc} 2$, rgnpc3 implicitly defined. The estimates for $\eta_{0}, \eta_{1}, \eta_{2}$ are reported in Table 1 . They are jointly significant for the three lowest education levels, but not for the highest level.

In order to check the validity of our model, we carried out the following misspecification test: we add to our model 55 arbitrarily chosen cohort dummies. ${ }^{16}$ Using a Wald test, we test the joint null hypothesis that the coefficients corresponding to the cohort dummies are equal to zero. If this null hypothesis is not rejected, we can conclude that cohort effects are effectively described by the three variables representing productivity growth.

A test of the model with rgnpc1, rgnpc2, rgnpc3 against a model which includes 55 extra cohort dummies does not lead to rejection. Table 1 shows that the p-values for the four education levels are respectively: .655, $.08, .879, .387$. Thus, our simple productivity model is capable of explaining all cohort differences in non-

\footnotetext{
${ }^{16}$ In our dataset, 60 different year-of-birth cohorts can be distinguished (1970 - 1911). Normally, we could add 59 cohort dummies to our model. However, since calendar year=year of birth+age, we only can add 58 dummies. Moreover, our model already contains 3 cohort-specific variables, namely rgnpc1, rgnpc 2 and rgnpc 3 . Consequently, we can only add 55 arbitrarily chosen cohort dummies and test for their joint significance.
} 
capital household income. ${ }^{17}$ Given that we have adequately modeled the cohort effects, we can pin down the time effects and the relationships between non-capital income and age.

Figure 5 presents the weighted average of RGNPC over the years when the head enters the labor market (16 to 25) as a function of birth-year (see equation (10)) for education level 1. Results are roughly the same for other education levels except for the highest education level for which we do not find an effect for RGNPC. The function is upward sloping for most of the cohorts, supporting the productivity growth hypothesis. While RGNPC increased steadily over time, it also experienced variation, particularly around the time of recessions. The nonlinear shape of this function is what allows us to distinguish among age, cohort and time effects.

One may worry that we have run into a spurious regression problem; apart from productivity growth, there may be other (unobserved cohort) effects which might explain non-capital income and which are positively correlated with the productivity growth variables. To investigate the importance of the spurious regression problem, we have added to our model a quadric cohort term, i.e., we add the variable year-of-birth squared. For all education levels, the coefficients corresponding to this added variable do not differ significantly from zero (the p-values are: $0.078,0.75,0.283,0.094)$. Furthermore, the variables rgnpc1, rgnpc2, rgnpc3 remain jointly significant for the first three education levels. Finally, Figure 5 remains unchanged if we use the estimates for the coefficients corresponding to the variables rgnpcl, rgnpc2, and rgnpc3 in the new specification.

\section{Econometric specification for wealth}

We now turn to the formulation of the empirical specification for wealth. Equation (4) serves as a starting point (note that $\mathrm{t}$ is an index for age):

$$
\frac{A_{t}}{Y_{p}}=(1+r)^{t-1}\left(\sum_{\tau=1}^{t}(1+r)^{1-\tau} \frac{\left(y_{\tau}-Y_{p}\right)}{Y_{p}}\right)-\alpha \frac{D S S_{t}}{Y_{p}}
$$

We construct permanent income using the estimated model for income. See appendix B for details on the construction of this measure. The first term on the right hand side is approximated by a linear spline in age

\footnotetext{
${ }^{17}$ Acceptance of the null of no (remaining) cohort effects also avoids the potential problem that the errors in the equation would exhibit a cohort effect. Such a structure would be different from the assumed error component structure where there are only individual effects and a white noise error term, and hence would invalidate all standard errors and statistical inferences drawn on the basis of them. In fact the Wald-test used here is closely related to the F-test proposed by Moulton and Randolph (1989) to detect group effects in the equation errors.
} 
(with 15 equally spaced knots), and adding demographics and education controls. As a result, the structure of the equation for wealth is quite similar to that for income. As explained in section 2 and appendix A, the second term of (11) measures the displacement effect of SS. The construction of this variable implies interactions of age and cohort effects. Thus, simple cohort dummies would not be able to approximate the effects of SS.

Note that, by dividing wealth by permanent income, we have already accounted for cohort effects in wealth due to productivity growth. Furthermore, if the PIH model were true, we do not need to add any additional cohort variables among our regressors. However, the permanent income model is only an approximation of the behavior towards wealth accumulation. Additionally, as found by King and Dicks-Mireaux (1982), preferences could be non-homothetic. Therefore, we add permanent income to the set of our right-hand-side variables (in some specifications, we simply add our RGNPC variables).

Since the wealth distribution is much more dispersed and rightly skewed than income, we estimate the model using median regressions. When using standard quantile regression routines available in statistical packages, we ignore the fact that households appear in the dataset more than once. This does not affect consistency of the parameter estimates. However, in the presence of unobserved individual effects, the (composite) error term is positively correlated within a household. By ignoring this positive correlation, we could underestimate the standard errors of the parameter estimates and overestimate the $t$-values. Therefore we compute the standard errors by using a bootstrapping technique which takes the positive within household correlation of the error terms into account (using the cluster option in the STATA bootstrap procedure).

\subsection{Empirical results for wealth}

Table 2 reports the estimation results for the two measures of wealth (net worth and financial wealth). Our constructed variable $D S S_{t}$ measuring the changes in SS is normalized by dividing by permanent income. For brevity, we do not present the estimated coefficients for the demographic variables, time dummies, learning dummies, and selectivity dummies but we only report the test for their significance. In the net worth equation, the selectivity dummies are jointly significant at the $1 \%$-level. The learning dummies are only significant at the $10 \%$-level for financial wealth. Many demographics are highly significant in both regressions.

We first discuss the estimates for net worth. As in King and Dicks-Mireaux (1982), we find strong evidence for non-homotheticity; the coefficients corresponding to permanent income and to its household specific average differs significantly from zero. The same applies to the RGNPC variables. The estimate corresponding to our constructed SS variable is highly significant and with the expected negative sign. Thus, 
there is evidence that Social Security displaced private wealth. An increase in the $D S S_{t}$-variable by Dfl 1,000 reduces net worth decreases by Dfl 115. As explained in section 2, in case of full displacement, we expect the coefficient of $D S S_{t}$ to be about 0.2 , while in our estimates we find a lower value which is significantly differ than 0.2 (the parameter estimate is equal to 0.115 with a standard error of 0.020 ).

Do additional cohort effects remain significant after accounting for permanent income and SS? We have tested for the existence of remaining cohort effects by adding 55 cohort dummies and examined their joint significance For net worth, these cohort dummies are not jointly significant at the 5\%-level $\left(\chi_{55}^{2}=71.46\right)$. Thus, we can meaningfully interpret the time effects and the age-net worth profiles to which we now turn.

Figure 6 displays the age-net worth profiles for different cohorts. The reference group consists of those households who lived in a time without SS (we named it "generation 0" since it is not present in our data set). The median age-net worth profile of this generation directly follows from the estimated coefficients corresponding to the linear spline age variables. Again, we have adopted a linear spline function with 15 equally spaced knots. The estimated coefficients corresponding to these variables are jointly significant $\left(\chi_{15}^{2}=375.98\right)$. The median age- net worth profile for generation 0 is hump-shaped; after age 65 median net worth decreases from Dfl. 200,000 to about Dfl. 130,000 at age 87 and the differences is statistically significant $\left(\chi_{1}^{2}=27.52\right)$.

Figure 6 also displays the age-net worth profile for the 1911 generation. This is the oldest generation in our dataset. The age-net worth profile is constructed by using the estimated coefficients from the linear age spline variables and the time path of the SS variable for this cohort. The profile for this generation is also humpshaped, but less so than that of generation 0 . The head of households in this generation was 36 years old when a first and very restricted form of SS was introduced in 1947. Consequently, until age 36, the age net worth profiles of the 1911 generation and generation 0 coincide. In 1957, the full SS legislation came into effect. Due to the introduction of and the changes in the SS legislation, the 1911 generation saved less for retirement than the generation without any SS. The level of displacement of SS can be read directly from the estimated coefficient corresponding to DSS (Table 2). Due to SS, the median household of the 1911 generation at age 65 had about Dfl 17,000 less net worth than the members of generation 0. Such is the difference at age 65 in predicted median net worth of the 1911 generation and of generation 0. After age 65, all households draw down their SS wealth. Since we have found evidence for a displacement effect of SS, the median household of the 1911 generation decumulates wealth at a slower pace than their counterparts of generation 0 .

In Figure 6, we also present the age-net worth profiles for the 1935 and 1946 generations. Since the SS 
legislation became more generous during the 1960s and 1970s, these generations have considerable more SS wealth than the 1911 generation. As a result, they display a less hump-shaped age-net worth profiles. Compared to older generations, younger generations who live through a period where SS was always present accumulated substantially less net worth.

To address the spurious regression problem, we have added again the variable year-of-birth squared (see column 3 of Table 2). This variable is not statistically significant (the absolute t-value is equal to 0.76 ). Moreover, the estimates for the other variables of interest (age and SS) are barely affected by the inclusion of this extra variable.

In the previous section, we allowed for education specific age-income profiles. We have also estimated net worth for each education level. When we consider all right hand side variables, we reject the null hypothesis that the regression coefficients are equal across education levels. However, we cannot reject the hypothesis that the age and DSS coefficients, our variables of interest, are equal across education level $\left(\chi_{48}^{2}=68.37\right)$. If we impose these restrictions, we again find evidence for a displacement effect of SS. The coefficient corresponding to DSS is equal to -0.074 (t-value: -5.11). The age net worth profiles are somewhat less humpshaped than the ones presented in Figure 6. For the 1935 and 1946 generations, we barely find evidence for decumulation of net worth during retirement.

In the last 2 columns of Table 2, we report the results for financial wealth. Note that in this case, the null hypothesis that there no remaining cohort effects, is rejected by the data $\left(\chi_{55}^{2}=1177.71\right)$. Strictly speaking, we cannot interpret the age-financial wealth profiles and we do not report a graph for this measure of wealth. The displacement effect of SS is smaller than in the case of total net worth. However, financial wealth represents a limited measure of accumulation and many Dutch households accumulate wealth in other assets (home equity, other real estate).

Again, we have investigated whether there is a serious spurious regression problem by adding the variable year-of-birth squared to the model (see last column of Table 2). This variable turns out to be significant for this measure of wealth. This is in line with our finding that we have not been able to model all cohort effects in the financial wealth equation. However, the coefficient corresponding to DSS is barely affected by the inclusion of this variable. We therefore cautiously conclude that we have found evidence for a displacement effect between financial wealth and SS.

We use the estimates in Table 2 to simulate the effect of a complete removal of SS. Results are reported in Table 3. Mean net worth would go up by about 15\% -from Dfl. 82,263 to Dfl. 95,362- and median net worth by about $36 \%$, if SS were abolished. Financial net worth would increase by about $10 \%$ in the mean and $25 \%$ 
in the median. Results are not much different using a specification which includes the variable year-of-birth squared. Thus, we find evidence that SS displaced wealth, and the effect is sizable when we consider medians. Changes in pension and SS currently at the center of the public policy debate in the Netherlands and other European countries can be expected to affect the accumulation of wealth in the future.

\section{Conclusion}

We have examined the income and wealth holdings of different cohorts. While many explanations have been given for observed differences between cohorts, disentangling these explanations is difficult. For example, simple cohort dummies cannot distinguish between differences in preferences and differences in economic circumstances. Our strategy consists of devising indicators that can summarize the economic conditions over time. A good proxy for the differences in the income profiles of households is the level of aggregate income per capita around the time the head of the household entered the labor market. Similarly, we have devised a proxy for the changes in the SS system at the beginning of or during the working life of the head of the household.

We find that the inclusion of a measure of productivity growth in our equations for income obviates the need to include cohort dummies. Similarly, productivity growth in permanent income and changes in SS can explain all cohort effects in wealth. Thus, past economic conditions can explain why generations differ in their wealth holdings.

Obviously, there are other economic conditions that could be important for explaining the differences in wealth accumulation, including precautionary motives, longevity, changes in house prices, bequest motives, changes in demographics and female labor supply. Undoubtedly, these factors play a role. The strategy in this paper has been, however, to simplify the model of wealth accumulation as far as possible while still being able to explain important features of the data. The fact that our two proposed economic indicators for productivity growth and SS are very effective in explaining the wealth holdings of different cohorts suggests that either

these other factors are very strongly correlated with our indicators, or that the other factors are of secondary importance in explaining the wealth accumulation of different cohorts. 


\section{Appendix A: Social Security and wealth holdings.}

We start the analysis by considering the closed-form solution for wealth in the PI-LCH. Throughout this appendix we carry out the analysis for a single individual of age $t$. Initially, we abstract from the impact of productivity growth on wealth holdings. In what follows, we maintain the assumptions that preferences are quadratic and intertemporally separable and that the interest rate equals the rate of time preference. The intertemporal budget constraint is written as:

$$
c_{t}=(1+r) A_{t-1}+y_{t}-A_{t}
$$

where $y_{t}$ is non-capital income at age $t, r$ is the interest rate, $A_{t}$ is wealth, and $c_{t}$ is consumption at age $t$. We adopt the convention that income (both capital income and non-capital income) is received at the end of each period; the same holds for the timing of consumption.

It is rather easy to see that consumption at age $t$ is equal to:

$$
c_{t}=\left(\sum_{\tau=t}^{L}(1+r)^{t-\tau}\right)^{-1}\left((1+r) A_{t-1}+\sum_{\tau=t}^{L}(1+r)^{t-\tau} E_{t} y_{\tau}\right)
$$

where $L$ is the time horizon, $E_{t}$ is the expectation operator conditional upon all information available at age $t$. From (A.1) and (A.2) one can derive that at age $t$, wealth $\mathrm{A}_{t}$ satisfies the following equation:

$$
\begin{aligned}
A_{t}= & (1+r)^{t} A_{0}+(1+r)^{t-1} y_{1}+(1+r)^{t-2} E_{1} y_{2}+. .+E_{1} y_{t}-\left(\frac{(1+r)^{t}-1}{r}\right) Y_{p I}+(1+r)^{t-2}\left(y_{2}-E_{1} y_{2}\right)+\ldots \\
& \left(y_{t}-E_{1} y_{t}\right)-\left(\left(\frac{(1+r)^{t-1}-1}{r}\right)\left(c_{2}-E_{1} c_{2}\right)+\left(\frac{(1+r)^{t-2}-1}{r}\right)\left(c_{3}-E_{2} c_{3}\right)+\ldots+\left(c_{t}-E_{t-1} c_{t}\right)\right)
\end{aligned}
$$

where $\mathrm{Y}_{\mathrm{p} 1}$ is permanent income evaluated in period 1 of the life cycle, defined as:

$$
Y_{p 1} \equiv\left(\sum_{\tau=1}^{L}(1+r)^{1-\tau}\right)^{-1}\left((1+r) A_{0}+\sum_{\tau=1}^{L}(1+r)^{1-\tau} E_{1} y_{\tau}\right)=c_{1}
$$

One can verify (A.3) by inserting the expressions for $A_{t}$ and $A_{t-1}$ into the intertemporal budget constraint (A.1) and by using the martingale property of consumption: $c_{t}=E_{t} c_{t+1}$.

The first part of (A.3) (until $Y_{p l}$ ) simply says that, in the absence of new information, wealth is equal to (expected) accumulated saving. During the life cycle, new information becomes available so that the consumer replans his/her consumption and wealth paths. The remainder of the equation displays the effects of the revisions in income and the revisions in the consumption path respectively. We can elaborate equation (A.3) further: 


$$
\begin{gathered}
A_{t}=(1+r)^{t} A_{0}+(1+r)^{t-1} y_{1}+(1+r)^{t-2} E_{1} y_{2}+. .+E_{1} y_{t}-\left(\frac{(1+r)^{t}-1}{r}\right) Y_{p I}+(1+r)^{t-2}\left(y_{2}-E_{1} y_{2}\right)+\ldots+\left(y_{t}-E_{1} y_{t}\right)- \\
\left(\frac{(1+r)^{t-1}-1}{r}\right)\left(\sum_{\tau=2}^{L}(1+r)^{2-\tau}\right)^{-1} \sum_{\tau=2}^{L}(1+r)^{2-\tau}\left(E_{2}-E_{1}\right) y_{\tau}- \\
\left(\frac{(1+r)^{t-2}-1}{r}\right)\left(\sum_{\tau=3}^{L}(1+r)^{3-\tau}\right)^{-1} \sum_{\tau=3}^{L}(1+r)^{3-\tau}\left(E_{3}-E_{2}\right) y_{\tau}-\ldots-\left(\sum_{\tau=t}^{L}(1+r)^{t-\tau}\right)^{-1} \sum_{\tau=t}^{L}(1+r)^{t-\tau}\left(E_{t}-E_{t-1}\right) y_{\tau}
\end{gathered}
$$

This expression is useful to highlight the effects on wealth of both the introduction of SS and later revisions in the level of SS. We assume that individuals hold static expectations concerning the future level of SS. ${ }^{18}$ That is, at each age , they plan their consumption as if the level of SS remains constant during the course of their lifetime. Furthermore, we initially assume that individuals ignore any possible feedback effect of SS on their current income (e.g. through a change in taxes). If a revision takes place, individuals update their expectations to the new SS level. One can use (A.5) to trace the effects of the introduction of SS and subsequent revisions on the accumulation of wealth.

Let's first consider the effect on wealth of someone who has not retired yet. Assume that individuals retire at age $L_{l}$, i.e. they start receiving SS in period $L_{l}+1$, so we consider the case where $t \leq L_{l}$. Using (A.5), we look at the effects of SS on $\mathrm{Y}_{\mathrm{p} 1}$. Let $S S_{1}$ be the level of SS anticipated by the individual when his age is 1 . Using (A.4) one sees that, relative to a situation without $\mathrm{SS}, \mathrm{Y}_{\mathrm{p} 1}$ is only affected by the term:

$$
\left(\sum_{\tau=1}^{L}(1+r)^{1-\tau}\right)^{-1}\left(\sum_{\tau=L_{1}+1}^{L}(1+r)^{1-\tau} S S_{1}\right)=(1+r)^{-L_{1}} \cdot \frac{1-(1+r)^{L_{1}-L}}{1-(1+r)^{-L}} \cdot S S_{1}
$$

Note that in (A.5) all income terms dated earlier than age $t$ are by assumption unaffected by changes in SS. The only other terms affected by changes in SS are the terms involving the update in expectations from one period to the next. For example, for $k \leq t$ we have the following effect of a change in SS at age $k$ :

$$
\sum_{\tau=k}^{L}(1+r)^{k-\tau}\left(E_{k}-E_{k-1}\right) y_{\tau}=\sum_{\tau=L_{1}+1}^{L}(1+r)^{k-\tau} \cdot S S_{k}^{*}=(1+r)^{k-L_{1}}\left[\frac{1-(1+r)^{L_{1}-L}}{r}\right] \cdot S S_{k}^{*}
$$

where $S S_{k}^{*}$ is the level of SS anticipated at age k, and $S S_{k}^{*}=S S_{k}-S S_{k-1}$ for $k \geq 2$.

Defining $S S_{1}{ }^{*}=S S_{1}$, and inserting (A.6) and (A.7) into (A.5) we obtain the following "displacement" effect of SS (in comparison to a world without SS) on the wealth holdings of individuals of age $t$ who are not retired yet:

${ }^{18}$ Or equivalently, that shocks in SS are taken to be permanent. 


$$
D S S_{t} \equiv-\sum_{k=1}^{t}\left(\frac{(1+r)^{t-k+1}-1}{(1+r)^{L-k+1}-1}\right)\left(\frac{(1+r)^{L-L_{1}}-1}{r}\right) S S_{k}^{*}, \text { for } t \leq L_{1}
$$

For retired individuals $\left(t>L_{1}\right)$ the analysis is quite a bit simpler. First, we note that the effect of SS on their wealth holdings at retirement (i.e. at the end of period $L_{l}$ ) is obtained from (A.8) by inserting $t=L_{l}$. This yields:

$$
D S S_{L_{1}}=-\sum_{k=1}^{L_{1}}\left(\frac{(1+r)^{L_{1}-k+1}-1}{(1+r)^{L-k+1}-1}\right)\left(\frac{(1+r)^{L-L_{1}}-1}{r}\right) S S_{k}^{*}
$$

Next we observe that under our assumptions, any change in SS after retirement is considered to be permanent by the individual, and hence translates into a corresponding change in consumption. As a result, wealth holdings after retirement are not affected by changes in SS that take place after $L_{l}$. Hence, the effect of SS on wealth holdings after retirement is obtained by considering the time path along which $D S S_{L l}$ is consumed towards the end of the life cycle. At each age, the following amount:

$$
c \equiv\left[\sum_{\tau=L_{1}+1}^{L}(1+r)^{L_{1}+1-\tau}\right]^{-1} \cdot D S S_{L_{1}}(1+r)=\frac{r}{1-(1+r)^{L_{1}-L}} \cdot D S S_{L_{1}}
$$

will be consumed. Thus at age $t>L_{l}$ the effect of SS on wealth holdings is equal to:

$$
\begin{gathered}
D S S_{t}=D S S_{L_{1}} \cdot\left[\frac{1-(1+r)^{t-L}}{1-(1+r)^{L_{1}-L}}\right]= \\
-\left(\frac{(1+r)^{L-L_{1}}-1}{r}\right) \cdot\left[\frac{1-(1+r)^{t-L}}{1-(1+r)^{L_{1}-L}}\right] \cdot \sum_{k=1}^{L_{1}}\left(\frac{(1+r)^{L_{1}-k+1}-1}{(1+r)^{L-k+1}-1}\right) S S_{k}^{*}
\end{gathered}
$$

Let us now relax the assumption that the introduction of SS does not affect the income of the working population. Instead we assume that, corresponding to a given level SS, a payroll tax is levied which is equal to $\alpha S S$. For simplicity we take $\alpha$ to be a constant. This would, for instance, correspond to a stationary population and a strict pay-as-you-go system. In that case, $\alpha$ is equal to the ratio of the number of SS recipients to the number of workers. We will see below that a generalization to a non-constant $\alpha$ is straightforward.

Once again we take (A.5) as a starting point. First consider the effect of the payroll tax associated with $S S_{I}$ on $Y_{p l}$. Using (A.4) we obtain a negative effect of a permanent payroll tax of $\alpha S S_{l}$ on $Y_{p l}$ equal to: 


$$
\alpha S S_{1}\left[\sum_{\tau=1}^{L}(1+r)^{1-\tau}\right]^{-1}\left(\sum_{\tau=1}^{L_{1}}(1+r)^{1-\tau}\right)=\alpha S S_{1} \frac{(1+r)^{L}-(1+r)^{L-L_{1}}}{(1+r)^{L}-1}
$$

In addition, the income terms on the first line of (A.5) up to $Y_{p l}$ are affected. The total effect of a payroll tax equal to $\alpha S S_{1}$ on these income terms is equal to:

$$
\left((1+r)^{t-1}+(1+r)^{t-2}+\ldots+1\right) \alpha S S_{1}=\frac{(1+r)^{t}-1}{r} \propto S S_{1}
$$

Combining (A.5), (A.12), and (A.13) we find the total negative effect of a payroll tax equal to $\alpha S S_{1}$ on wealth accumulation at age $t$ to be equal to:

$$
\alpha S S_{1} \frac{(1+r)^{t}-1}{r}\left(\frac{(1+r)^{L-L_{1}}-1}{(1+r)^{L}-1}\right)
$$

Now consider the effect of a change in SS at age $k$. This effect also consists of two parts. The first part is:

$$
\left[(1+r)^{t-k}+(1+r)^{t-k-1}+\ldots+1\right] \alpha S S_{k}^{*}=\frac{(1+r)^{t-k+1}-1}{r} \alpha S S_{k}^{*}
$$

The second part is:

$$
\begin{gathered}
-\alpha S S_{k}^{*}\left(\frac{(1+r)^{t-k+1}-1}{r}\right)\left(\sum_{\tau=k}^{L}(1+r)^{k-\tau}\right)^{-1}\left(\sum_{\tau=k}^{L_{1}}(1+r)^{k-\tau}\right)= \\
-\alpha S S_{k}^{*}\left[\frac{1+r)^{t-k+1}-1}{(1+r)^{L-k+1}-1}\right]\left[\frac{(1+r)^{L-k+1}-(1+r)^{L-L_{1}}}{r}\right]
\end{gathered}
$$

Adding both parts yields:

$$
\alpha S S_{k}^{*}\left[\frac{(1+r)^{t-k+1}-1}{r}\right]\left[\frac{(1+r)^{L-L_{1}}-1}{(1+r)^{L-k+1}-1}\right]
$$

Comparing (A.17) to (A.14) shows that (A.17) applies for all $k$, also $k=1$. Finally, by aggregating over all $k \leq t$, we obtain the following total effect of the payroll tax on wealth at age $t$ :

$$
-\alpha \sum_{k=1}^{t} S S_{k}^{*}\left[\frac{(1+r)^{t-k+1}-1}{r}\right]\left[\frac{(1+r)^{L-L_{1}}-1}{(1+r)^{L-k+1}-1}\right]
$$

Comparing this to (A.8), we observe that apart from a factor $\alpha$, (A.18) is exactly equal to (A.8). The intuition for this is straightforward. Under the assumptions made, consumption is constant across the life cycle. Given the age of retirement, savings during the working life are exclusively a function of the difference in incomes 
between retirement and the working life. An increase in income during retirement therefore has exactly the same effect as a reduction in income during the working life.

A generalization to the case where the payroll tax varies across age is straightforward. The factor $\alpha$ is replaced by $\alpha_{k}$ and in (A.18) $\alpha_{k}$ is moved under the summation sign. Finally, the case where $t>L_{l}$ is an obvious adaptation of (A.11): one simply pre-multiplies (A.11) by $\alpha$. The total effect of SS after retirement and a payroll tax before retirement is $(1+\alpha)$ times (A.8) and (A.11) respectively. In our empirical work, we compute (A.8) and (A.11) for all possible ages $t$ and for all generations we observe in our sample. 


\section{Appendix B: Construction of permanent income measures}

To construct permanent income, we use the estimated income equations to predict future non-capital incomes of all households in the sample. Permanent income at age $t$ is equal to (suppressing the household index $h)$ :

$$
Y_{p t}=B_{t}^{-1} \sum_{\tau=t}^{L}(1+r)^{t-\tau} E_{t} y_{\tau}
$$

with

$$
B_{t} \equiv \sum_{\tau=1}^{L}(1+r)^{t-\tau}=\frac{(1+r)\left[1-(1+r)^{t-(L+1)}\right]}{r}
$$

The expression for $E_{t} y_{\tau}$ follows from Equations (6) and (7) in the text, under the additional assumption that the error term $\epsilon_{t h}$ is normally distributed. We consider two cases.

The first case is where all right hand side variables are assumed to remain constant as of age $t$, except age. We can then summarized Equations (6) and (7) as:

$$
\ln \left(y_{\tau}\right)=X_{t}+f(\tau)+\epsilon_{\tau}
$$

where $f(\tau)$ is the age function and $X_{t}$ represents the influence of all other explanatory variables (including the individual effect). The expression for expected future incomes then becomes:

$$
E_{t} y_{\tau}=\exp \left[X_{t}+f(\tau)+\frac{1}{2} \sigma_{\epsilon}^{2}\right]
$$

Inserting this expression into (B.1) yields the permanent income variable to be used in the wealth regression.

The second case arises if we drop the assumption that the right hand side variables of the income equation will remain constant if one grows older. In particular, family composition may change in predictable ways. Thus, in the second case, we estimate an auxiliary equation which predicts household composition when age increases. This prediction is next used to update $X_{t}$ as the household heads ages. Equation (B.4) is now replaced by:

$$
E_{t} y_{\tau}=\exp \left[X_{\tau}+f(\tau)+\frac{1}{2} \sigma_{\epsilon}^{2}\right]
$$

In the empirical section of this paper we predict future income using equation (B.5). We have, however, experimented with using equation (B.4) instead of (B.5). The results are not affected by this choice. 


\section{References}

Alessie, R., A. Lusardi, and A. Kapteyn (1995), "Saving and Wealth Holdings of the Elderly," Research in Economics, 49, 293-315.

Alessie, R., A. Lusardi, and T. Aldershof (1997), "Income and Wealth Over the Life Cycle: Evidence from Panel Data," Review of Income and Wealth, 43, 1-32.

van Ark, B., J. de Haan, and H.J. de Jong (1996), "Characteristics of Economic Growth in the Netherlands During the Post-War Period," in N. Crafts and G. Toniolo (eds.), Economic Growth in Europe since 1945, Cambridge, UK: Cambridge University Press.

Attanasio, O. (1998), "A Cohort Analysis of Saving Behavior by US Households," Journal of Human Resources, 33, 575-609.

Attanasio, O. and H. Hoynes (2000), "Differential Mortality and Wealth Accumulation," Journal of Human Resources, 35, 1-29.

Browning M. and A. Lusardi (1996), "Household Saving: Micro Theories and Micro Facts," Journal of Economic Literature, 34, 1797-1855.

Browning, M., A. Deaton, and M. Irish (1985), "A Profitable Approach to Labour Supply and Commodity Demands Over the Life-Cycle," Econometrica, 53, 503-544.

Camphuis, H. (1993), "Checking, Editing and Imputation of Wealth Data of the Nerherlands Socio-Economic Panel for the period 87-89," VSB Progress Report n. 10, CentER, Tilburg University, The Netherlands.

Deaton (1999), "Saving and Growth" in K Schmidt-Hebbel and L. Serven (eds), "The Economics of Saving and Growth: Theory, Evidence and Implications for Policy,", Cambridge: Cambridge University Press, 33-70.

Deaton, A. and C. Paxson (1994a), "Saving, Growth and Aging in Taiwan," in D. Wise (ed.) Studies in the Economics of Aging, Chicago: University of Chicago Press, 331-357.

Deaton, A. and C. Paxson (1994b), "Intertemporal Choice and Inequality," Journal of Political Economy, 102, 
437-467.

Diamond, P.A. and J.A. Hausman (1984), “Individual Retirement and Savings Behavior,” Journal of Public Economics, 23, 81-114.

Feldstein, M. (1974), "Social Security, Induced Retirement, and Aggregate Capital Accumulation," Journal of Political Economy, 82, 905-925.

Feldstein, M. (1996),"Social Security and Saving: New Time Series Evidence," National Tax Journal, 49, 151164.

Heckman, J. and R. Robb (1985), "Using Longitudinal Data to Estimate Age, Period and Cohort Effects in Earnings Equations," in W. Mason and S. Fienberg (eds.), Cohort Analysis in Social Research Beyond the

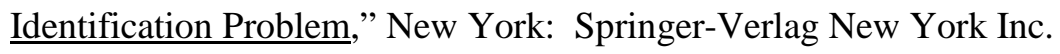

Hubbard, G.R., J. Skinner, and S.P. Zeldes (1995), “Precautionary Saving and Social Insurance,” Journal of Political Economy, 103, 360-399.

Hurd, M. (1998), "Mortality Risk and Consumption by Couples,” mimeo, RAND.

Hurd, M. (1990), "Research on the Elderly: Economic Status, Retirement, and Consumption and Saving," Journal of Economic Literature, 28, 565-637.

Hurd, M. (1989), “Mortality Risk and Bequests,” Econometrica, 57, 779-813.

Hurst, E., M.C. Luoh, and F.P. Stafford (1998), "Wealth Dynamics of American Families: 1984-1994," Brookings Papers on Economic Activity, 1, 267-337.

Jappelli, T. (1999), "The Age-Wealth Profile and the Life-Cycle Hypothesis: A Cohort Analysis with a Time Series of Cross-Sections of Italian Households," Review of Income and Wealth, 45, 57-76.

Jonsson, A. and A. Klevmarken (1978), "On the Relationship Between Cross-Sectional and Cohort Earning Profiles," Annales de l'INSEE, 331-53. 
Kapteyn, A. and K. de Vos (1998), "Social Security and Labor-Force Participation in The Netherlands," American Economic Review, 88, 164-167.

King, M.A., L-D. L. Dicks-Mireaux (1982), “Asset Holdings and the Life-Cycle”, Economic Journal, 92, 247-267

MaCurdy, T. and T. Mroz (1995), "Measuring Macroeconomic Shifts in Wages From Cohort Specifications," mimeo, Stanford University.

Moulton, B.R. and W.C.R. Randolph (1989), "Alternative Tests of the Error Component Model," Econometrica, 57, 685-693.

Mundlak, Y. (1978),"On the Pooling of Time Series and Cross Section Data," Econometrica, 46, 69-85.

Samwick, A. (2003), "Patience, Pensions, and Saving”, working paper, Dartmouth College.

Shorrocks, A.F. (1975), "The Age-Wealth Relationship: A Cross Section and Cohort Analysis," Review of Economics and Statistics, 155-163.

Venti, S. and D. Wise (1997), "The Wealth of Cohorts: Retirement Saving and the Changing Assets of Older Americans,"in S. Schieber and J. Shoven (eds.), "Public Policy Toward Pensions," Cambridge: Twentieth Century Fund and MIT Press.

Viard, A. (1993), "The Productivity Slowdown and the Saving Shortfall: A Challenge to the Permenent Income Hypothesis," Economic Inquiry, 31, 549-564.

Verbeek, M. and T. Nijman (1992), “Testing for Selectivity Bias in Panel Data Models,” International Economic Review, 681-703.

Weiss, Y. and L. Lillard (1978), "Experience, Vintage and Time Effects in the Growth of Earnings: American Scientists, 1960-1970," Journal of Political Economy, 86, 427-447. 


\begin{tabular}{|c|c|c|c|c|}
\hline \multicolumn{5}{|c|}{$\begin{array}{l}\text { Table 1: Estimation results for income, by education level } \\
\text { Dependent variable is logarithm of non-capital income }\end{array}$} \\
\hline & Educ level 1 & Educ level 2 & Educ. level 3 & Educ level 4 \\
\hline rgnpc1 & $\begin{array}{ll}0.070 \\
(1.01)\end{array}$ & $\begin{array}{l}0.058 \\
(0.70)\end{array}$ & $\begin{array}{l}0.059 \\
(0.81)\end{array}$ & $\begin{array}{l}0.107 \\
(1.09)\end{array}$ \\
\hline rgnpc2 & $\begin{array}{l}-0.082 \\
(1.89)\end{array}$ & $\begin{array}{l}-0.034 \\
(0.65)\end{array}$ & $\begin{array}{l}-0.037 \\
(0.79)\end{array}$ & $\begin{array}{l}-0.102 \\
(1.59)\end{array}$ \\
\hline rgnpc3 & $\begin{array}{l}0.011 \\
(2.33)^{*}\end{array}$ & $\begin{array}{l}0.005 \\
(0.89)\end{array}$ & $\begin{array}{l}0.005 \\
(1.01)\end{array}$ & $\begin{array}{l}0.012 \\
(1.75)\end{array}$ \\
\hline Number of observations & 11,479 & 9,084 & 18,427 & 12,401 \\
\hline Number of households & 1,922 & 1,484 & 2,782 & 2,012 \\
\hline log likelihood & $-4,314.81$ & $-3,180.22$ & $-3,923.71$ & $-5,057.91$ \\
\hline Joint significance RGNPC coefficients & $\begin{array}{l}\chi_{3}^{2}: 16.28 \\
\text { Pval }=0.001\end{array}$ & $\begin{array}{l}\chi_{3}^{2}: 25.87 \\
\text { Pval }=0.000\end{array}$ & $\begin{array}{l}\chi_{3}^{2}: 24.82 \\
\text { Pval }=0.000\end{array}$ & $\begin{array}{l}\chi_{3}^{2}: 5.55 \\
\text { Pval }=0.136\end{array}$ \\
\hline Joint significance age-spline coefficients & $\begin{array}{l}\chi_{15}^{2}: 93.84 \\
\text { Pval }=0.000\end{array}$ & $\begin{array}{l}\chi_{15}^{2}: 102.96 \\
\text { Pval }=0.000\end{array}$ & $\begin{array}{l}\chi_{15}^{2}: 411.98 \\
\text { Pval }=0.000\end{array}$ & $\begin{array}{l}\chi_{15}^{2}: 1045.53 \\
\text { Pval }=0.000\end{array}$ \\
\hline $\begin{array}{l}\text { Test against a model with a full set of age } \\
\text { dummies }\end{array}$ & $\begin{array}{l}\chi_{52}^{2}: 56.46 \\
\text { Pval }=0.312\end{array}$ & $\begin{array}{l}\chi_{52}^{2}: 67.8 \\
\text { Pval }=0.070\end{array}$ & $\begin{array}{l}\chi_{52}^{2}: 55.34 \\
\text { Pval }=0.350\end{array}$ & $\begin{array}{l}\chi_{52}^{2}: 56.08 \\
\text { Pval }=0.325\end{array}$ \\
\hline Joint significance time dummies & $\begin{array}{l}\chi_{13}^{2}: 16.76 \\
\text { Pval }=0.211\end{array}$ & $\begin{array}{l}\chi_{13}^{2}: 16.18 \\
\text { Pval }=0.239\end{array}$ & $\begin{array}{l}\chi_{13}^{2}: 18.47 \\
\text { Pval }=0.214\end{array}$ & $\begin{array}{l}\chi_{13}^{2}: 26.54 \\
\text { Pval }=0.014\end{array}$ \\
\hline Joint significance learning dummies & $\begin{array}{l}\chi_{13}^{2}: 11.11 \\
P v a l=0.601\end{array}$ & $\begin{array}{l}\chi_{13}^{2}: 19.18 \\
P v a l=0.118\end{array}$ & $\begin{array}{l}\chi_{13}^{2}: 59.78 \\
P v a l=0.000\end{array}$ & $\begin{array}{l}\chi_{13}^{2}: 15.00 \\
P v a l=0.308\end{array}$ \\
\hline Joint significance selectivity dummies & $\begin{array}{l}\chi_{15}^{2}: 9.87 \\
\text { Pval }=0.627\end{array}$ & $\begin{array}{l}\chi_{15}^{2}: 8.23 \\
\text { Pval }=0.767\end{array}$ & $\begin{array}{l}\chi_{15}^{2}: 18.21 \\
\text { Pval }=0.109\end{array}$ & $\begin{array}{l}\chi_{15}^{2}: 13.90 \\
\text { Pval }=0.307\end{array}$ \\
\hline $\begin{array}{l}\text { Test against a model with a full set of cohort } \\
\text { dummies }\end{array}$ & $\begin{array}{l}\chi_{55}^{2}: 50.3 \\
\text { Pval }=0.655\end{array}$ & $\begin{array}{l}\chi_{55}^{2}: 70.3 \\
\text { Pval }=0.08\end{array}$ & $\begin{array}{l}\chi_{55}^{2}: 43.04 \\
\text { Pval }=0.879\end{array}$ & $\begin{array}{l}\chi_{55}^{2}: 57.38 \\
\text { Pval }=0.387\end{array}$ \\
\hline
\end{tabular}

Note: This table reports the estimates of the productivity growth variables in the income regressions. Estimation is performed separately by education level. Absolute value of t-statistics are reported in parentheses. For brevity, estimates of other variables are not reported, but the table reports tests of their joint significance. Refer to Section 4 for a complete list of the variables included in the regressions. 


\begin{tabular}{|c|c|c|c|c|}
\hline \multicolumn{5}{|c|}{$\begin{array}{l}\text { Table 2: Estimation results for net worth and financial net worth } \\
\text { Dependent variable is wealth divided by permanent income }\end{array}$} \\
\hline & \multicolumn{2}{|c|}{ Net worth } & \multicolumn{2}{|c|}{ Financial net worth } \\
\hline & Specific. I & Specific. II & Specific. I & Specific. II \\
\hline DSS & $\begin{array}{l}-0.115 \\
(5.64)^{* *}\end{array}$ & $\begin{array}{l}-0.108 \\
(5.26)^{* *}\end{array}$ & $\begin{array}{l}-0.02 \\
(3.10)^{* *}\end{array}$ & $\begin{array}{l}-0.018 \\
(3.51)^{* *}\end{array}$ \\
\hline rgnpc1 & $\begin{array}{l}0.155 \\
(0.71)\end{array}$ & $\begin{array}{l}0.138 \\
(0.61)\end{array}$ & $\begin{array}{l}-0.008 \\
(0.13)\end{array}$ & $\begin{array}{l}-0.041 \\
(0.67)\end{array}$ \\
\hline rgnpc2 & $\begin{array}{l}-0.004 \\
(0.03)\end{array}$ & $\begin{array}{l}-0.003 \\
(0.03)\end{array}$ & $\begin{array}{l}0.016 \\
(0.42)\end{array}$ & $\begin{array}{l}0.015 \\
(0.39)\end{array}$ \\
\hline rgnpc3 & $\begin{array}{l}0.001 \\
(0.06)\end{array}$ & $\begin{array}{l}0.001 \\
(0.07)\end{array}$ & $\begin{array}{l}0 \\
(0.44)\end{array}$ & $\begin{array}{l}-0.001 \\
(0.24)\end{array}$ \\
\hline Permanent income & $\begin{array}{l}-0.277 \\
(2.85) * *\end{array}$ & $\begin{array}{l}-0.262 \\
(2.70) * *\end{array}$ & $\begin{array}{l}-0.059 \\
(2.56)^{*}\end{array}$ & $\begin{array}{l}-0.052 \\
(2.28)^{*}\end{array}$ \\
\hline $\begin{array}{l}\text { Permanent income (household specific } \\
\text { average) }\end{array}$ & $\begin{array}{l}0.851 \\
(7.48)^{* * *}\end{array}$ & $\begin{array}{l}0.829 \\
(7.01)^{* *}\end{array}$ & $\begin{array}{l}0.162 \\
(5.94) * *\end{array}$ & $\begin{array}{l}0.153 \\
(5.61)^{* *}\end{array}$ \\
\hline year-of-birth ${ }^{2}$ & & $\begin{array}{l}-0.000 \\
(0.76) \\
\end{array}$ & & $\begin{array}{l}-0.000 \\
(5.25) * *\end{array}$ \\
\hline Number of observations & 41,105 & 41,105 & 41,057 & 41,057 \\
\hline $\begin{array}{l}\text { p-value } \chi^{2} \text {-test joint significance rgnpc } \\
\text { coefficients }\end{array}$ & 0.000 & 0.001 & 0.167 & 0.492 \\
\hline $\begin{array}{l}\text { p-value } \chi^{2} \text {-test joint significance time } \\
\text { dummies }\end{array}$ & 0.000 & 0.000 & 0.022 & 0.000 \\
\hline $\begin{array}{l}\text { p-value } \chi^{2} \text {-test joint significance selectivity } \\
\text { dummies }\end{array}$ & 0.000 & 0.000 & 0.083 & 0.509 \\
\hline $\begin{array}{l}\text { p-value } \chi^{2} \text {-test joint significance learning } \\
\text { dummies }\end{array}$ & 0.146 & 0.096 & 0.091 & 0.059 \\
\hline $\begin{array}{l}\text { p-value } \chi^{2} \text {-test joint significance age spline } \\
\text { variables }\end{array}$ & 0.000 & 0.000 & 0.000 & 0.000 \\
\hline $\begin{array}{l}\text { Test against model with a full set of cohort } \\
\text { dummies ( } p \text { value) }\end{array}$ & 0.067 & & 0.000 & \\
\hline
\end{tabular}

Note: This table reports the estimates of the variables measuring productivity growth and Social Security in the wealth regressions using median regressions (absolute value of t-statistics are in parentheses). For brevity, estimates of other variables are not reported, but the table reports tests of their joint significance. Refer to Section 5 for a complete list of the variables included in the regressions. 


\begin{tabular}{|l|l|l|l|l|}
\hline \multicolumn{5}{|c|}{ Table 3: The effects of Social Security on wealth } \\
\hline $\begin{array}{l}\text { Main } \\
\text { model }\end{array}$ & $\begin{array}{l}\text { Net Worth } \\
(\text { mean })\end{array}$ & $\begin{array}{l}\text { Net Worth } \\
\text { (median) }\end{array}$ & $\begin{array}{l}\text { Financial Net Worth } \\
(\text { mean })\end{array}$ & $\begin{array}{l}\text { Financial Net Worth } \\
\text { (median) }\end{array}$ \\
\hline $\begin{array}{l}\text { Sample } \\
\text { values }\end{array}$ & 82,263 & 35,346 & 21,292 & 6,800 \\
\hline Without SS & 95,362 & 48,206 & 23,619 & 9,083 \\
\hline Main model with year-of-birth & & & 6,800 \\
\hline $\begin{array}{l}\text { Sample } \\
\text { values }\end{array}$ & 82,263 & 35,346 & 21,292 & 8,790 \\
\hline Without SS & 94,544 & 47,350 & 23,319 & \\
\hline
\end{tabular}

Note: This table reports the sample values of total and financial net worth and the estimated values of total and financial net worth if Social Security were abolished. Estimates are based on the main specification reported in equation (11) in the text and a specification with a quadratic cohort term. 
Figure 1a: The effect of the introduction of Social Security on consumption

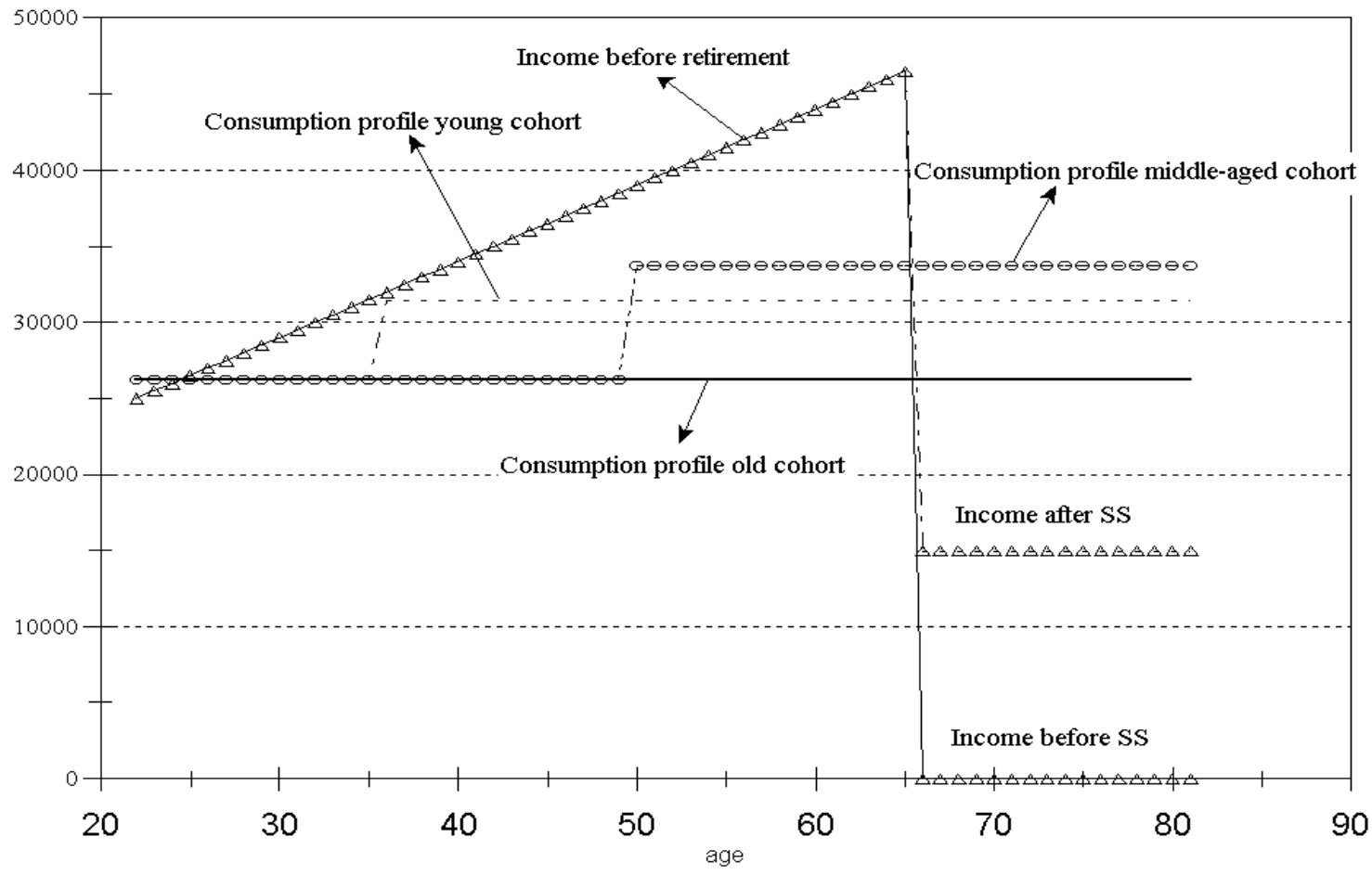

Figure 1b: The effect of the introduction of Social Security on wealth

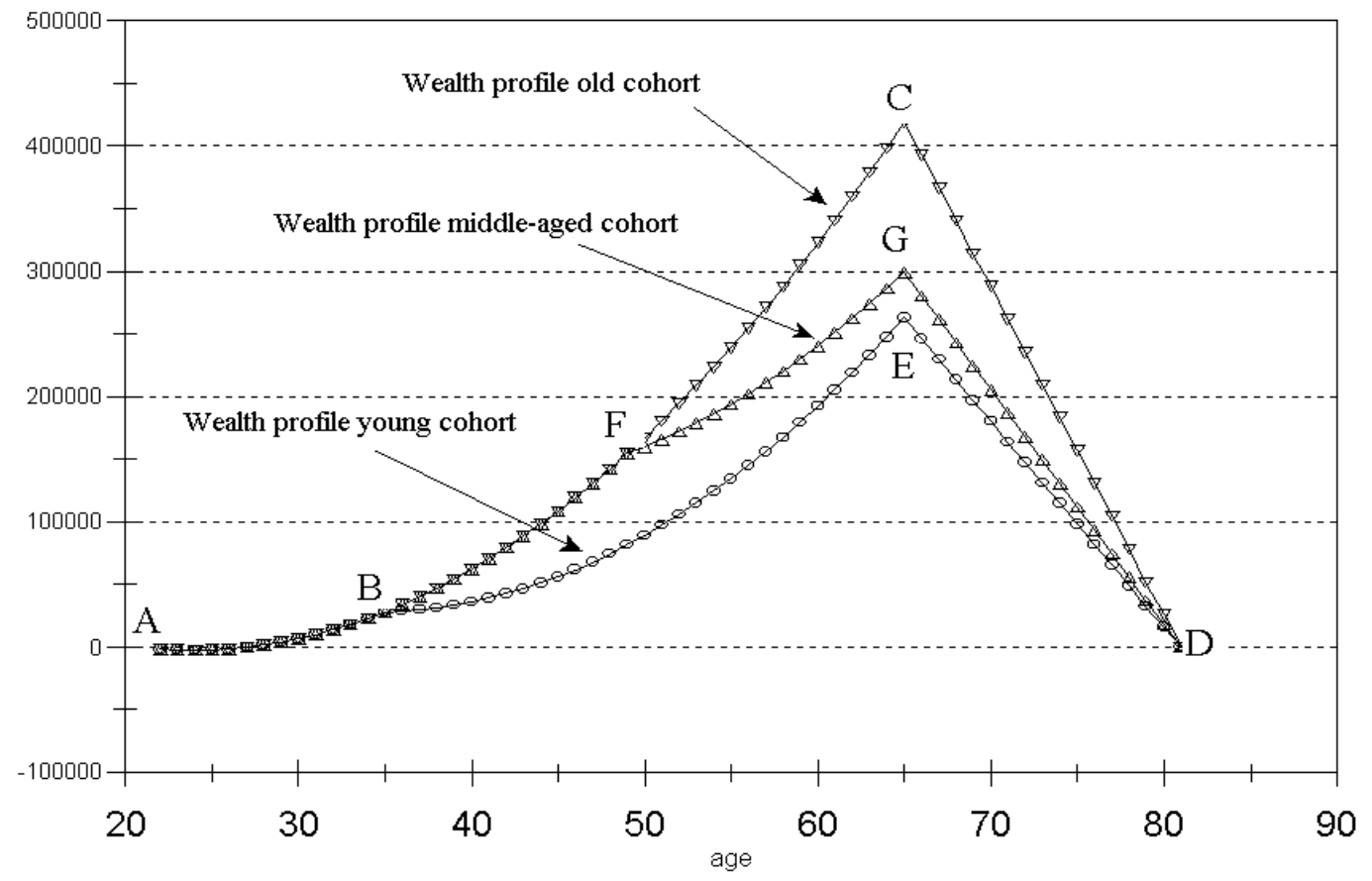




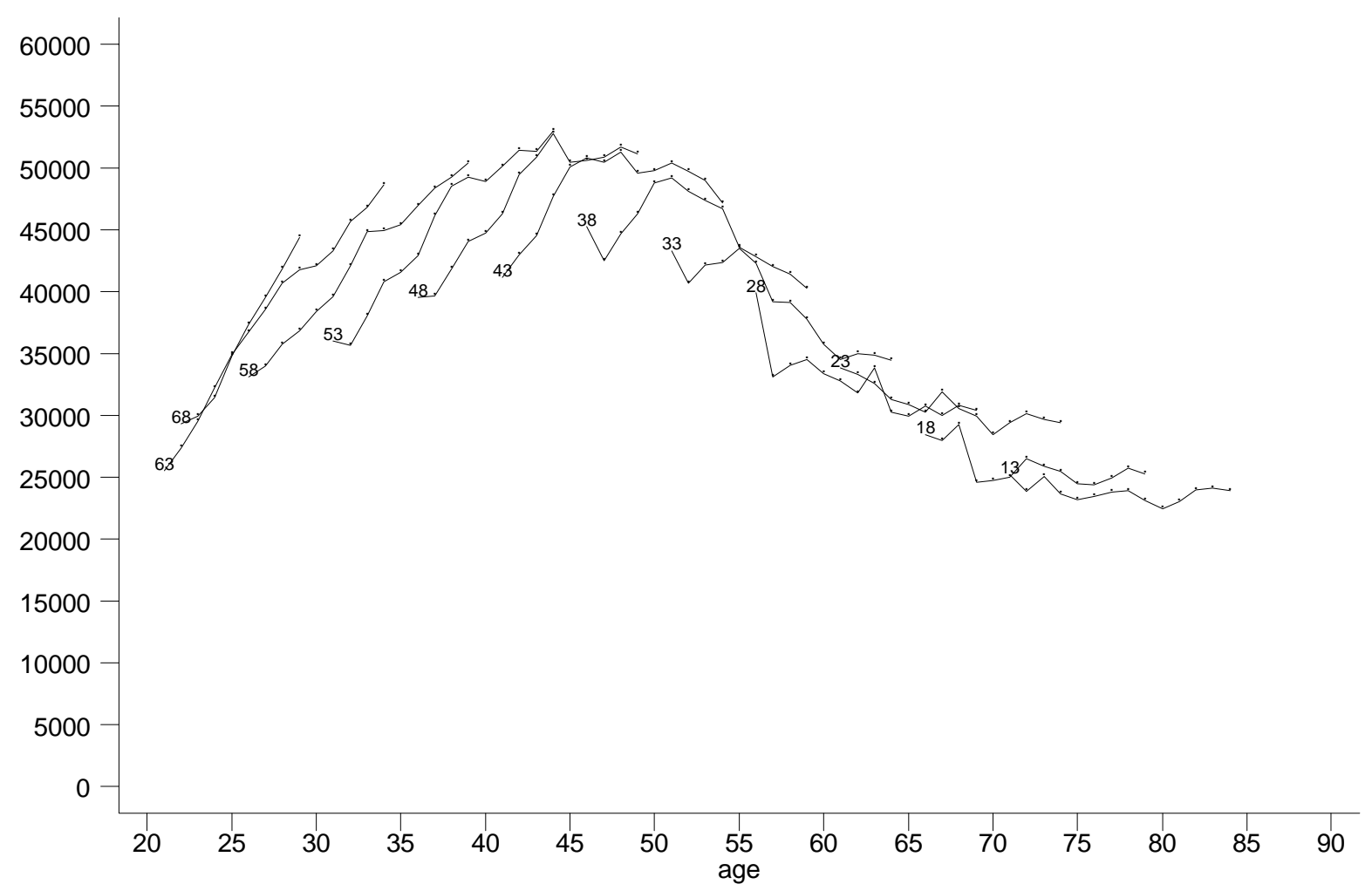

Figure 2: Average non capital income by age and cohort 


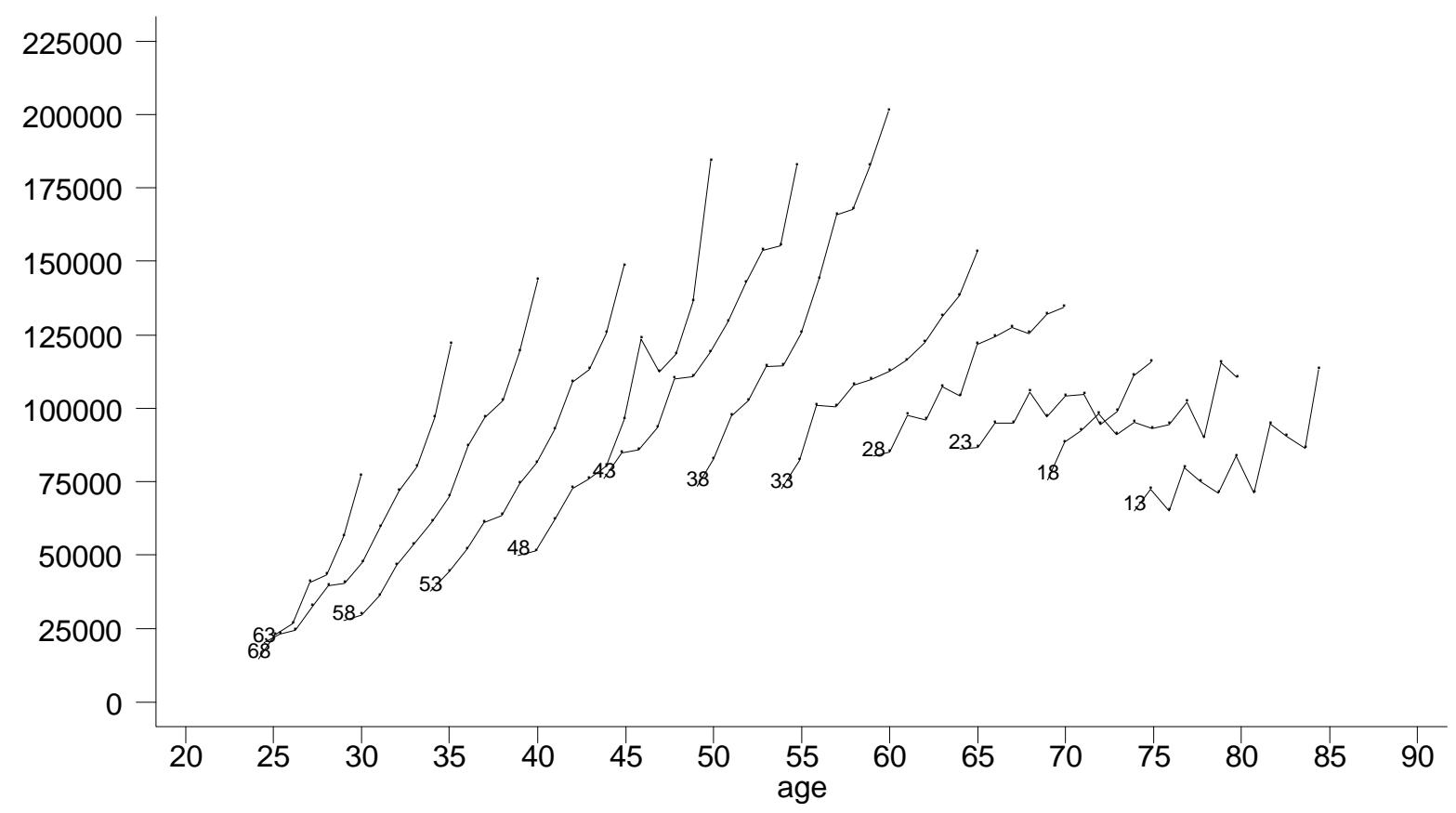

Figure 3a: Average net worth by age and cohort

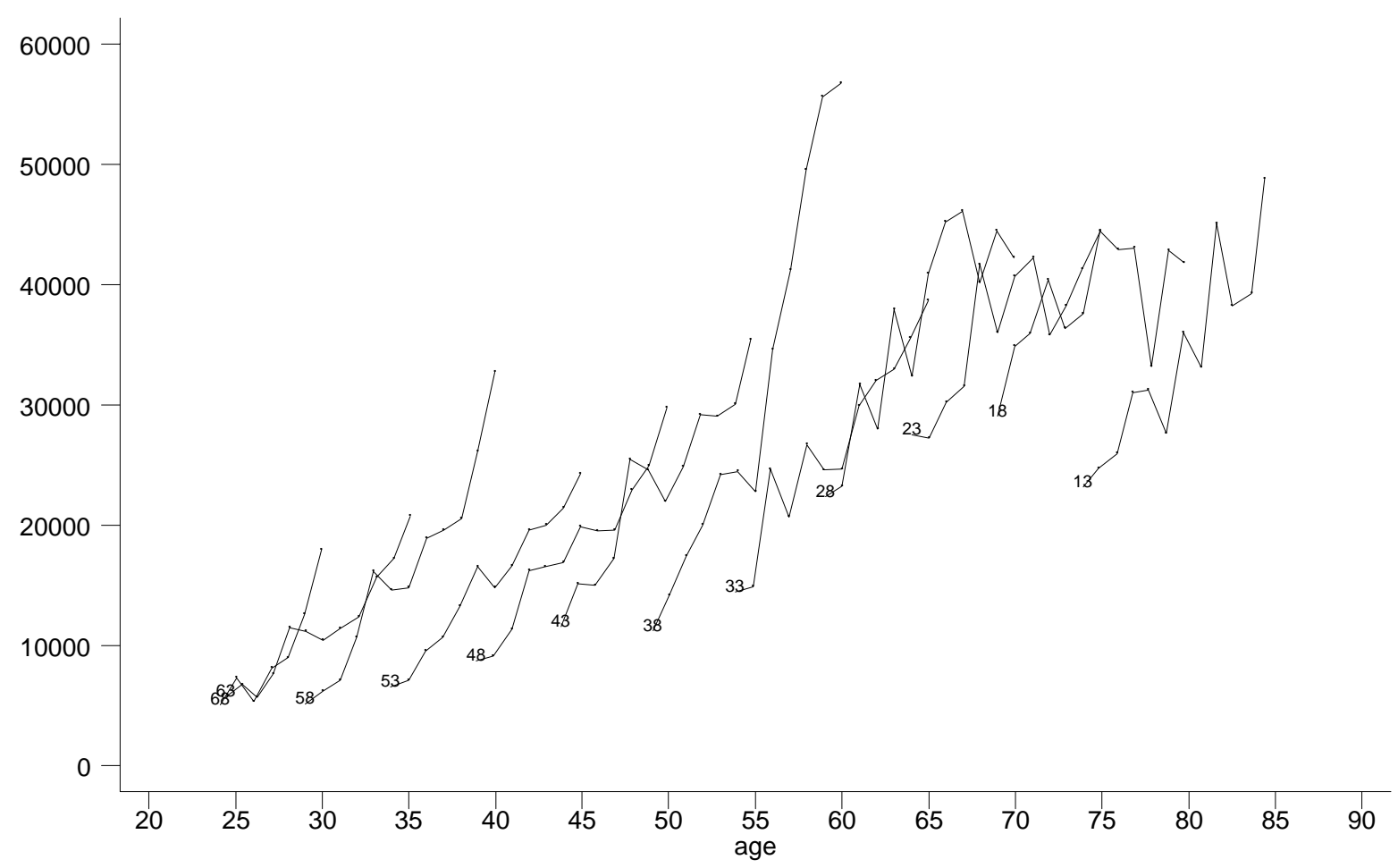

Figure 3b: Average financial wealth by age and cohort 


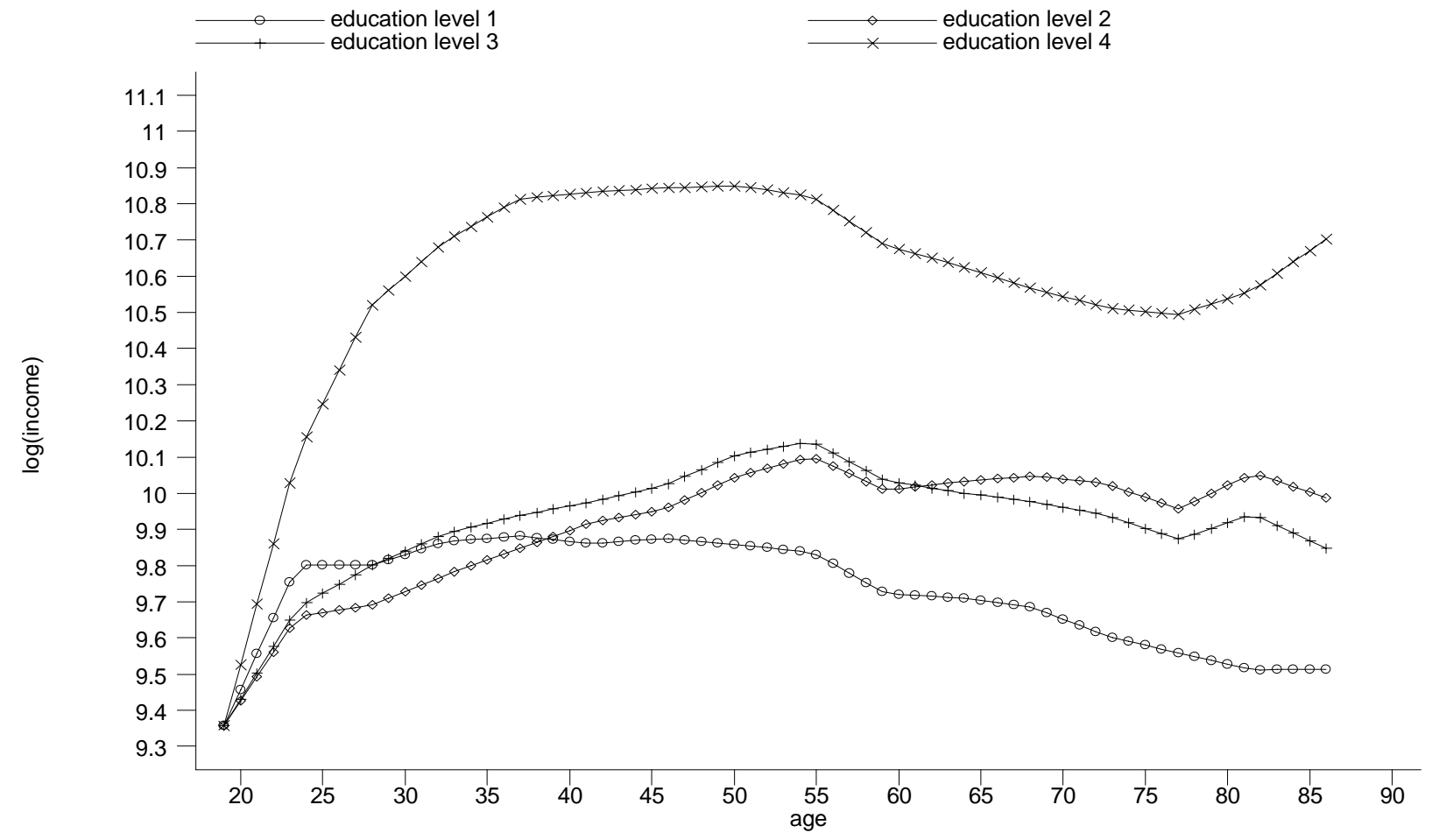

Figure 4: Education specific age-log(income) profiles

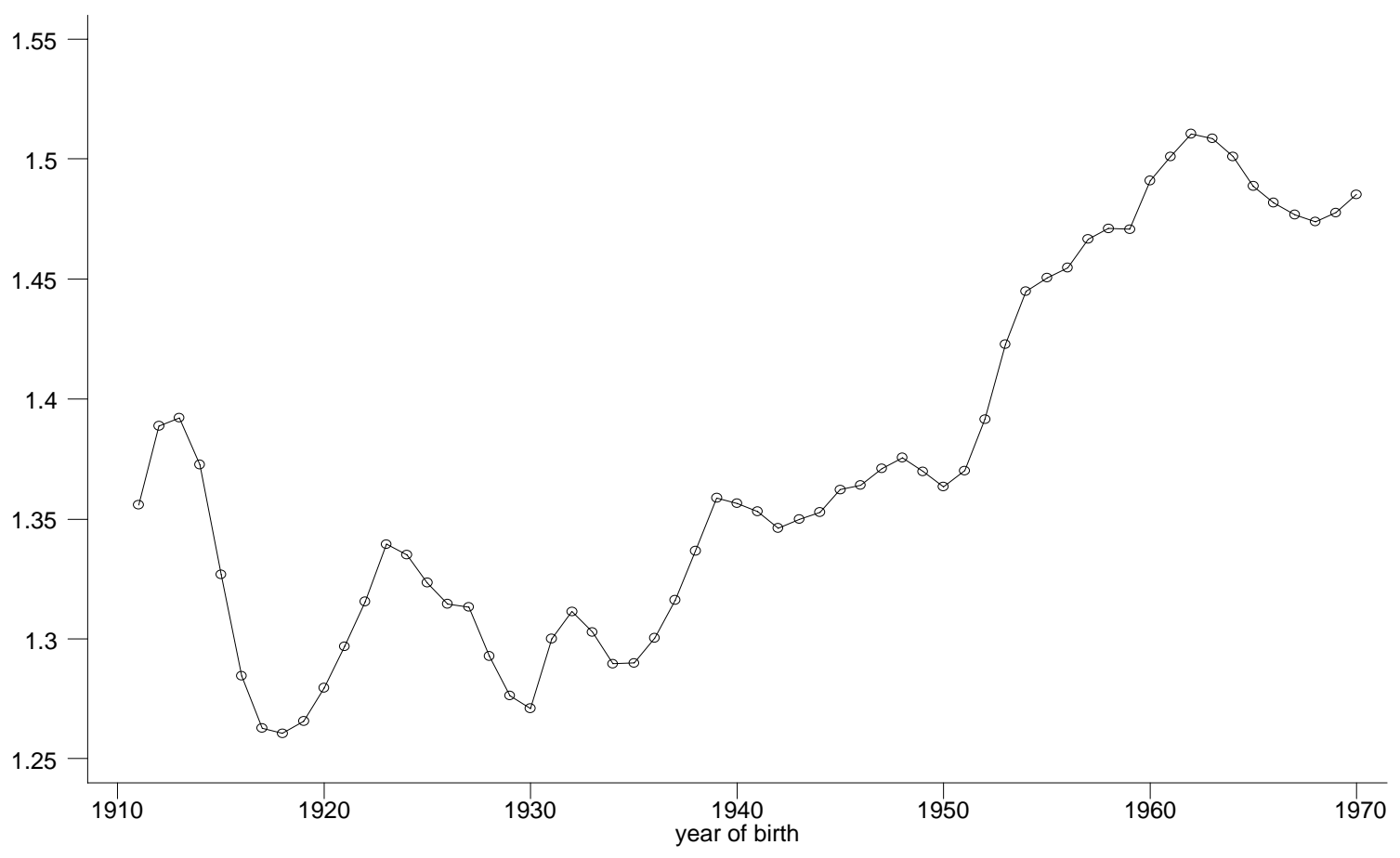

Figure 5: Productivity of different cohorts for household heads with primary education 


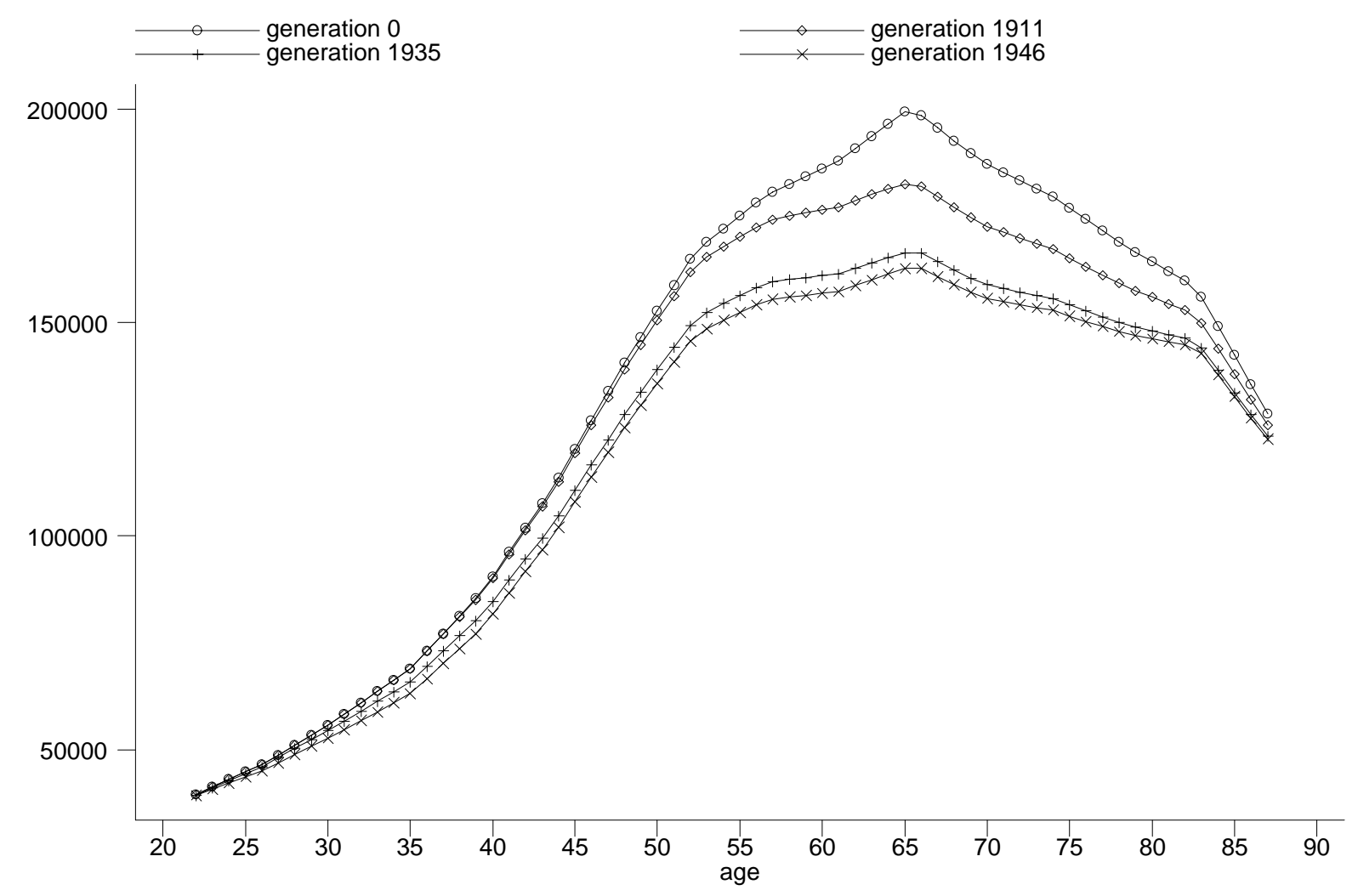

Figure 6: Age net worth profiles for different cohorts 